\title{
Thermal and porosity properties of meteorites : A compilation of published data and new measurements
}

Soini, A-J

2020-02

Soini , A-J , Kukkonen , I T , Kohout , T \& Luttinen , A 2020 , ' Thermal and porosity properties of meteorites : A compilation of published data and new measurements ', Meteoritics and Planetary Science, vol. 55 , no. 2 , pp. 402-425 . https://doi.org/10.1111/maps.13441

http://hdl.handle.net/10138/325033

https://doi.org/10.1111/maps.13441

cc_by

acceptedVersion

Downloaded from Helda, University of Helsinki institutional repository.

This is an electronic reprint of the original article.

This reprint may differ from the original in pagination and typographic detail.

Please cite the original version. 
Thermal and porosity properties of meteorites: A compilation of published data and new measurements

\author{
A.-J. Soini ${ }^{1,}{ }^{*}$, I. T. Kukkonen ${ }^{1}$, T. Kohout ${ }^{1}$, A. Luttinen ${ }^{2}$ \\ ${ }^{1}$ Department of Geosciences and Geography, University of Helsinki, P.O. Box 64, FI-00014 \\ Helsinki, Finland \\ ${ }^{2}$ Finnish Museum of Natural History, University of Helsinki, P.O. Box 44 FI-00014, Helsinki, \\ Finland \\ *Corresponding author. E-mail: assi-johanna.soini@helsinki.fi
}

"This is the peer reviewed version of the following article: Soini, A.-J., Kukkonen, I.T., Kohout, T. and Luttinen, A. (2020), Thermal and porosity properties of meteorites: A compilation of published data and new measurements. Meteorit Planet Sci, 55: 402-425. doi:10.1111/maps.13441, which has been published in final form at 10.1111/maps.13441. This article may be used for noncommercial purposes in accordance with Wiley Terms and Conditions for Use of Self-Archived Versions."

\begin{abstract}
We report direct measurements of thermal diffusivity and conductivity at room temperature for 38 meteorite samples of 36 different meteorites including mostly chondrites, and thus almost triple the number of meteorites for which thermal conductivity is directly measured. Additionally, we measured porosity for 34 of these samples. Thermal properties were measured using optical infrared scanning method on samples of cm-sizes with a flat, sawn surface. A database compiled from our measurements and literature data suggests that thermal diffusivities and conductivities at room temperature vary largely among samples even of the same petrologic and chemical type and overlap among e.g. different ordinary chondrite classes. Measured conductivities of ordinary chondrites vary from 0.4 to $5.1 \mathrm{~W} / \mathrm{m} / \mathrm{K}$. On average, enstatite chondrites show much higher values $(2.33-5.51$ $\mathrm{W} / \mathrm{m} / \mathrm{K})$ and carbonaceous chondrites lower values $(0.5-2.55 \mathrm{~W} / \mathrm{m} / \mathrm{K})$. Mineral composition (silicates vs. iron-nickel) and porosity control conductivity. Porosity shows (linear) negative correlation with conductivity. Variable conductivity is attributed to heterogeneity in mineral composition and porosity by intra- and intergranular voids and cracks, which are important in the scale of typical meteorite samples. The effect of porosity may be even more significant for thermal properties than that of the metal content in chondrites.
\end{abstract}

\title{
1. Introduction
}

General. Thermal properties of meteorites (thermal conductivity, thermal diffusivity, heat capacity, thermal inertia) are essential variables in quantitative modeling of Solar System processes, evolution and state of asteroids and small bodies, e.g. asteroid differentiation processes. Especially, measured thermal conductivity values for meteorites will have a significant impact in the modeling of small body thermal evolution and metamorphism.

Porosity, including intragranular, intergranular, and shock induced porosity, is an important factor affecting thermal properties in asteroids and meteorites along with metal content. Thus, modeling thermal evolution of asteroids requires estimations of their internal structure. Macro porosities show profound variability indicating that the objects range from solid and coherent objects (low macro porosity) to loosely consolidated rubble piles (high macro porosity) (Britt et al. 2002). According to Ostrowski and Bryson (2017), porosity correlates negatively with shear modulus and Young's modulus in particular providing clues on mechanical properties of chondrite bodies. Most of the large mass stony meteorites are products of showers whose fragments are compositionally homogeneous 
implying small stony bodies are usually homogeneous and weak rubble piles (Scheeres et al. 2015). While the individual components can be very strong, the asteroid as a whole is very weak (Scheeres et al. 2015).

Consolmagno et al. (2008) report that, in the case of S-type asteroids, macro porosity with significant fractures appears to increase with distance from the Sun. Macro porosity of C-type asteroids is usually higher than that of S-type asteroids. For example, asteroids Bennu and Ryugu have macro porosities around 50\%. According to Michel (2014), macro porosity may cause the density between S-type asteroids and their meteorite analogues to differ, while some micro porosity, corresponding to small pores with approximately uniform and isotropic distribution, may be required to elucidate the lower bulk density of C-type asteroids. Unfortunately, there is no direct evidence of the nature of porosity inside an asteroid, even regarding asteroids for which density has been estimated (Michel 2014).

C-type asteroids are extremely dark, while S-type asteroids are bright due to the missing carbon compounds. Typically, dark asteroids are thought to have a bulk density of $1.0-1.3 \mathrm{~g} / \mathrm{cm}^{3}$ (e.g. Yeomans et al. 1997) which is lower compared to the $2.0-2.7 \mathrm{~g} / \mathrm{cm}^{3}$ bulk densities typical of bright asteroids (e.g. Abe et al. 2006). Comparing the bulk densities of asteroids with those of their assumed meteorite analogues yields porosity estimates for asteroids. Many asteroids appear to have considerable porosities since their bulk densities seem to be well below the grain density of their likely meteorite analogues (Britt et al. 2002). Assuming fractures follow the Weibull distribution (Weibull 1951), in which fractures are assumed to be randomly distributed within the object, the likelihood of fractures increases along with the size of the object. Bryson et al. (2015) noted that scaling the meteorite fractures to the nature of fragmentation of asteroids follows the Weibull distribution. However, Kohout (2009) noted that there is a scale problem in comparing meteorites to asteroids since differences exist on various scales between sample returns, meteorite measurements, and observations of asteroids. The differences are due to sub-mm to km scales of inhomogeneity of asteroids (e.g. mineralogical and structural heterogeneities) and $\mathrm{dm}$ to sub-mm scales of inhomogeneity of meteorites (e.g. clasts, inclusions, chondrules) (Kohout 2009).

Thermal properties. Thermal conductivity is a measure of the ability of a material to conduct heat. Thermal conductivity is defined by

$$
q=-k \nabla T
$$

where $q$ is the heat flux, $k$ is the thermal conductivity, and $\nabla T$ is the temperature gradient. Thermal diffusivity $\alpha$ describes the rate of temperature spread through a material, and it links thermal conductivity with density and specific heat capacity as follows:

$$
\alpha=\frac{k}{\rho c_{p}},
$$

where $\rho$ is the density, and $c_{p}$ is the specific heat capacity. Thus, thermal diffusivity is directly proportional to thermal conductivity and inversely proportional to specific heat capacity, which is the measure of the amount of heat energy necessary to increase the temperature of a unit quantity of the material by a given temperature interval. Thermal diffusivity has physical relevance in the framework of transient conduction processes. Since thermal diffusivity is a measure of the ability of a material to conduct thermal energy relative to its ability to store thermal energy, high thermal diffusivity translates to high conduction rate relative to heat storage capacity and rapid response to changes in temperature, and thus rapid heat transfer.

Thermal conductivities of meteorites are poorly quantified, and the data of Opeil et al. $(2010,2012)$ are among the first direct measurements. Due to differences in mineralogy (e.g. amount and types of metal) and physical properties (e.g. density, porosity), thermal conductivity of meteorites varies 
significantly. Published thermal conductivity data on meteorites whose porosity has been determined are particularly rare (Flynn et al. 2018). Consequently, measured thermal diffusivity values have been used to determine thermal conductivity values of ordinary chondrites (Yomogida and Matsui 1983, Matsui and Osako 1979). Szurgot and Wojtatowicz (2011) reported thermal diffusivity measurements and Szurgot (2011) reported thermal conductivities for meteorites derived from these measurements in the form of conference abstracts.

Aim of the present study. This study focuses on thermal conductivity, diffusivity, and porosity of chondrites, but data on iron meteorites and a stony iron meteorite are also reported. We used a contactless method to simultaneously measure both thermal conductivity and thermal diffusivity at room temperature. In addition, porosities were determined from densities and volumes acquired with a gas pycnometer and 3D laser scanning measurements. We also provide a compiled dataset of previously reported results on thermal conductivity and porosity properties of meteorites measured to date. We compare our measured data and earlier results, describe differences between meteorite classes, and test relationships between thermal conductivity and porosity, thermal diffusivity and porosity, and thermal conductivity and bulk density. To study the effect of varying porosity and metal content on thermal conductivity, we calculated geometric mean models for meteorites with different theoretical compositions.

\subsection{Review of previous measurements}

Few direct thermal conductivity measurements are reported in the literature. Matsui and Osako (1979) and Yomogida and Matsui (1983) presented the only systematic work to date regarding thermal conductivities of meteorites. They reported thermal diffusivity measurements of 21 ordinary chondrites under vacuum $(<0.1 \mathrm{~Pa})$ at six temperatures from 100 to $350 \mathrm{~K}$ using the modified Ångström's method, and used them to calculate thermal conductivities (Eq. 2). They calculated the heat capacities of the samples from the mineralogy of the meteorites and measured grain densities using a helium pycnometer. Bulk densities of samples shaped as rectangular parallelepipeds were calculated from the mass and the volume of the samples, otherwise the modified Archimedean method was used to determine bulk densities. Porosity was calculated from the sample densities. They also studied the effect of weathering on their results and did not find any systematic difference between the physical properties of falls and finds or correlation of physical properties with the amount of rust in their samples, and concluded that their results are not distorted by weathering effects.

In Yomogida and Matsui (1983), the range of thermal conductivities at $300 \mathrm{~K}$ is $0.63-3.54 \mathrm{~W} / \mathrm{m} / \mathrm{K}$ for $\mathrm{H}$ chondrites and $0.4-2.55 \mathrm{~W} / \mathrm{m} / \mathrm{K}$ for $\mathrm{L}$ chondrites. The ranges of conductivity values for these $\mathrm{H}$ and $\mathrm{L}$ chondrites at $200 \mathrm{~K}$ are $0.8-3.9 \mathrm{~W} / \mathrm{m} / \mathrm{K}$ and $0.4-2.3 \mathrm{~W} / \mathrm{m} / \mathrm{K}$, respectively. Thus, the spread in their results is substantial, and the values for $\mathrm{L}$ chondrites overlap with the values of $\mathrm{H}$ chondrites, although $\mathrm{L}$ chondrites generally have slightly lower conductivities than $\mathrm{H}$ chondrites. However, this is not the case considering the reported conductivities in Opeil et al. (2012), where the range of conductivities for both $\mathrm{L}$ and $\mathrm{H}$ chondrites is broad and significantly overlapping. Note that most of the samples in Yomogida and Matsui (1983) are finds whereas most of the samples in Opeil et al. (2010, 2012) are falls. It is worth noting that all these values are remarkably lower than the conductivities of olivine, pyroxene, and plagioclase (Opeil et al. 2010), and the results by Yomogida and Matsui (1983) show that ordinary chondrites are significantly less conductive than one would calculate simply from the constituent minerals. In addition, Opeil et al. (2012) reported that the measured conductivities of the stony meteorites are lower by as much as an order of magnitude compared to literature values for pure minerals that the meteorite is composed of (Clauser and Huenges 1995). Yomogida and Matsui (1983) observed that some lower-porosity samples have much larger thermal diffusivity than other porous samples. They calculated theoretical conductivities for ordinary chondrites from their normative mineral compositions using thermal conductivity values of individual minerals and the formulae derived by Hashin and Shtrikman (1962), and concluded that 
the theoretical values are clearly higher than the measured thermal conductivity of porous and cracked samples.

Opeil et al. (2010, 2012) used a Quantum Design Physical Properties Measurement System, Thermal Transport Option (TTO), to measure thermal conductivity of samples cut into regular parallelepipeds of 2-6 mm dimension (Opeil et al. 2010) and 0.5-1 cm prisms (Opeil et al. 2012) at low temperatures $(5-300 \mathrm{~K})$. A heater attached to one end of the sample applies a heat pulse that generates a temperature difference between two thermometers at the sample ends. The sample was measured in a vacuum and the pressure was held to $<1.33 \times 10^{-4} \mathrm{~Pa}$. Opeil et al. (2012) stated that the instrument error is generally about $0.01 \mathrm{~W} / \mathrm{m} / \mathrm{K}$. Their samples included 17 stony meteorites (11 ordinary chondrites, 2 enstatite chondrites, 2 carbonaceous chondrites, 2 basaltic achondrites) and one iron meteorite. While the results of Opeil et al. $(2010,2012)$ are of higher precision and examine a broader range of temperatures and meteorite types, they agree well with previous studies, where conductivity was determined from diffusivity and modeled heat capacities. They calculated bulk densities based on the regular shapes of the samples, and grain densities were taken from the averages of unweathered meteorites of given class. Porosities were calculated based on the densities.

The difficulty of using a heat pulse by an attached heater lies in establishing a good contact between the heater and the sample. If the contact is insufficient, thermal conductivity will be underestimated (Hofmeister and Pertermann 2008). On the other hand, thermal conductivity measurement using a laser flash method to provide heat via a pulse may lead to erroneous results if the transfer of energy through the crystal by laser photons, rather than phonons is not sufficiently attributed, which leads to overestimation of thermal conductivity (Opeil et al. 2010).

Most studies, e.g. Opeil et al. (2010, 2012), cover temperatures up to about $300 \mathrm{~K}$. Opeil et al. (2012) observed that conductivities remained nearly constant above $100 \mathrm{~K}$ as phonon activation energies are reached and the transport of the phonons depends mostly on the occupancy and orientation of cracks, which impede the heat flow consistently at all temperatures. Thus, at around $100 \mathrm{~K}$, the conductivity values reach the highest point and then slowly decrease as temperature increases, and thermal conductivities of meteorites may virtually be assumed constant with temperature above $100 \mathrm{~K}$ (Opeil et al. 2012). This agrees with the phonon conduction theory (Debye et al. 1914, Hofmeister et al. 2007), since at low temperatures conductivity is proportional to the $\mathrm{T}^{3}$ ( $\mathrm{T}$ is absolute temperature), but at high temperatures to 1/T. Crystal boundaries, impurities, cracks, and anharmonic coupling affect the temperature, at which the maximum conductivity is reached.

Szurgot and Wojtatowicz (2011) measured thermal diffusivities of 18 meteorite samples including eight chondrites using the Laser Flash Method at ambient conditions, at $298 \mathrm{~K}$ in $1 \mathrm{~atm}$, and determined the bulk densities using the Archimedean method. They reported the relative errors of diffusivity to be about $1-6 \%$, and density about $1 \%$. Based on the measured thermal diffusivities, Szurgot (2011) derived the thermal conductivities $K$ of the meteorites at room temperature from the relationship $K=D d C_{p}$, where $D$ is thermal diffusivity, $d$ is bulk density, and $C_{p}$ is specific heat capacity.

\section{Materials and methods}

\subsection{Materials}

The 38 samples of this study represent 36 meteorites including two carbonaceous chondrites, one enstatite chondrite, 29 ordinary chondrites, three irons, and one stony iron meteorite (11 falls and 25 finds) from the meteorite collection of the Finnish Museum of Natural History, University of Helsinki. Chondrites Plainview (H5) and Arcadia (LL6) had two samples. Samples were selected based on their shapes and cut surfaces. The masses of the samples vary from $3.7 \mathrm{~g}$ to $403 \mathrm{~g}$ with an average of $56 \mathrm{~g}$, sizes from $3.5 \mathrm{~cm}$ to $9.3 \mathrm{~cm}$ with an average of $6 \mathrm{~cm}$, and volumes from $1.02 \mathrm{~cm}^{3}$ to $125.9 \mathrm{~cm}^{3}$ with an average of $16 \mathrm{~cm}^{3}$. Porosities vary from $2 \%$ to $26 \%$ with an average of $11 \%$. 
All measurements were carried out on samples as such without any extra preparation. All of the meteorite samples used for measurement of thermal properties are cut slabs and some of them are polished, so that the surface requirements of the thermal conductivity scanning instrument are satisfied (see section 2.2).

Varying degrees of terrestrial weathering can be seen in finds, most obviously in the form of iron oxides. In addition, most of the measured falls in this study date back to the nineteenth century and minor weathering effects are probable. Arcadia (LL6), Cope (H5), Covert (H5), Ferguson Switch (H5), McKinney (L4), Neenach (L6), and Plainview (H5) have obvious fractures, which are expected to affect heat transport. Alfianello (L6), Allende (CV3), Beenham (L5), Holbrook (L/LL6), and Valkeala (L6) are partially covered with fusion crust. However, only the measurement surface of Alfianello had fusion crust. Irons Bella Roca (III AB) and Canyon City (III AB) exhibit Widmanstätten pattern. An oval troilite (iron sulfide) inclusion in Bendego (Iron, IC) was not in the measurement path of the thermal conductivity scanning instrument.

\subsection{Thermal properties}

Thermal conductivity and diffusivity were measured using TCS Optical scanner (The Thermal Conductivity and Diffusivity Meter, TCS Lippmann \& Rauen GbR), which applies a high precision, noncontact method based on optical scanning (e.g. Popov et al. 1985). The optical scanning technology is based on scanning a sample surface with a focused, mobile, and continuously operated near-point-like optical heat source conjointly with infrared temperature sensors. The sensor "cold" is aligned exactly to the scanning line and measures the temperature before heating, while sensor "hot" measures the temperature after heating approximately 7 millimeters off the scanning line. Thermal properties are determined by comparing the temperature differences measured on standard samples with known thermal properties with the temperature differences measured on the sample. Thermal conductivity and thermal diffusivity were measured at room temperature, and the precision of the instrument is $3 \%$ for a confidential probability of 0.95 for conductivity measurements and $5 \%$ for thermal diffusivity measurements. Measurement range for conductivity is from $0.2 \mathrm{~W} / \mathrm{m} / \mathrm{K}$ to 25 $\mathrm{W} / \mathrm{m} / \mathrm{K}$ and for thermal diffusivity from $0.6 \mathrm{~mm}^{2} / \mathrm{s}$ to $3.0 \mathrm{~mm}^{2} / \mathrm{s}$.

Popov et al. (1999) compared three different laboratory methods including the method used in this study, as well as half-space line source and divided bar methods for thermal conductivity measurements based on an extensive collection of rock samples. Regardless of the inhomogeneity of thermal conductivity and high anisotropy of the samples, the results of the different methods were found consistent.

With TCS, it is possible to measure thermal conductivity and thermal diffusivity simultaneously using TC+TD -mode. As results of the scanning, profiles of thermal properties along the scanning line, inhomogeneity of thermal properties, and components of the thermal properties tensor for anisotropic solids (anisotropy) are obtained in addition to the recorded values for thermal conductivity and diffusivity.

The measured samples need to have a flat or a cylindrical surface, and the minimum length along the scanning line is four centimeters. The minimum thickness depends on the sample's thermal conductivity, and the minimum width is equal to the minimum thickness. These can be determined from the nomograms in the instrument documentation. Acceptable sample surface is smooth with maximum spatial deviations of $\pm 0.5 \mathrm{~mm}$. All of the measurement surfaces of our samples complied the instrument requirements.

In order to homogenize the sample surface emissivity for the TCS scanning, the surface has to be prepared black. Usually this is done with black paint, but in the case of meteorite samples it is not permitted. Therefore, Scotch ${ }^{\circledR}$ Magic ${ }^{\mathrm{TM}}$ Tape was applied to prepare the meteorite samples, since it is thin enough and easy to apply and remove from the surface without damaging the sample. We tested the effect of the tape and the paint on thermal conductivity by measuring test samples with 
known thermal conductivity using paint, as well as both tape and paint and the results were consistent. The tape was carefully attached to the sample preventing any air pockets from forming underneath the tape. After this, the tape was colored. We tested different types of paints to minimize the influence of varying optical reflection coefficients, and the best results were obtained using gouache paint with varnish. Gouache provides a deep black and matte finish, which is suitable to prevent optical reflection. In addition, gouache has the advantage of being very opaque with only a small amount of coating. It also dries quickly and provides an even surface regarding thickness and roughness with no brush marks. The thickness of the colored tape is approximately the same as that of the tape itself; 50-60 $\mu \mathrm{m}$. Using a coat of varnish provides a scratch resistant surface and prevents fingerprints.

Thermal conductivity and thermal diffusivity were measured four times for each sample to test reproducibility, and the average of these values is reported for every sample. Thermal measurements were conducted in two orthogonal directions for 23 samples to see if anisotropy occurs in conductivity. Some of the samples lack porosity determination as their sizes exceeded the volume of the sample cell of the gas pycnometer.

\subsection{Porosity}

We measured the masses of the meteorites using Ohaus Scout ${ }^{\circledR}$ Pro scale with maximum capacity of $400 \mathrm{~g}$ and resolution of $0.01 \mathrm{~g}$. Mass error is considered insignificant comparative to volume error. We used a gas pycnometer, Quantachrome Ultrapyc 1200e, which provides a non-destructive method, to measure the grain volume of the meteorite samples. The instrument measures the volume impassable to nitrogen, which corresponds to the "grain volume" of the sample. The sample cells are up to $135 \mathrm{~cm}^{3}$. It is noteworthy that the sample volume and preparation influence the precision and reproducibility. For example, the temperature of the sample should be similar in subsequent measurement. The instrument automatically takes ten measures and reports the average value of the grain volume and the average volume standard deviation. Grain density of the sample was calculated from the measured grain volume and the sample mass. Wilkison et al. (2003) performed an analysis of a typical pycnometer, and reported that when estimating porosity, the grain volume error dominates the uncertainty and is relatively higher in smaller sized samples. The accuracy and repeatability of Quantachrome Ultrapyc 1200e are $< \pm 0.02 \%$ and $< \pm 0.01 \%$, respectively, for sample cell sizes of $135 \mathrm{~cm}^{3}$ and $50 \mathrm{~cm}^{3}$. For the smallest sample cell of $10 \mathrm{~cm}^{3}$ the accuracy and repeatability are $< \pm$ $0.03 \%$ and $< \pm 0.015 \%$, respectively.

$3 \mathrm{D}$ laser scanning possibly provides the least invasive technique in determining the bulk volume of a meteorite. As a method, it is non-destructive with no physical or chemical contamination of the meteorite. We used triangulation laser scanner, NextEngine 3D Scanner Ultra HD model 2020i, for the measurements. First step was to acquire image data. Second step was to build a volumetric 3D model of the meteorite. Finally, Geomagic Verify Viewer program was used to determine the volume of the 3D model. Bulk density was calculated based on the measured bulk volume. Theoretical 1- $\sigma$ uncertainties in volumetric measurements using NextEngine 3D laser scanner at high resolution are about $0.4 \%$ for a $1 \mathrm{~cm}^{3}$ sample and decrease with sample size to $0.02 \%$ for samples above $40 \mathrm{~cm}^{3}$ (Macke et al. 2015).

Erroneous textures and morphologies may occur especially in 3D scanning at high resolutions, if the distance of the meteorite from the scanner is not in the ideal range of the instrument. The sizes of the meteorites in this study did not appear to present problems during scanning. However, sharp edges and angles may create partially obstructed paths for the laser planes, and this may lead to weak reflections that may not be detected. This in turn leads to visible scars in the 3D model. Fusion crust present in some of the meteorites may result in detection of only a weak specular reflection at some incident angles of the laser planes, which may cause holes in the point cloud data and influence image alignment. In addition, the 3D model building process may lead to distortion of volumes if trimming of image edges is excessive or insufficient. 
Porosity of the samples was calculated from the acquired grain and bulk density. The uncertainty of porosity was determined by calculating the combined uncertainty using summation in quadrature, or the root sum of the squares.

\subsection{Geometric mean models}

We calculated theoretical models to predict the thermal conductivity of ordinary chondrites. McSween et al. (1991) reported the average and standard deviations of normative minerals for ordinary chondrite classes. Generalizing, two thirds of the bulk composition of ordinary chondrites is comprised of olivine and hypersthene, which belongs to the group of orthorhombic pyroxenes, and metal or Fe-Ni alloys (kamacite and taenite) and sulfide (troilite) constitute most of the remainder.

Normative mineralogies provide a feasible estimation of the modal mineralogy for ordinary chondrites (Dodd 1981, McSween et al. 1991). Chondrule abundance in ordinary chondrites is 60-80 vol\%, and matrix abundance 10-15 vol\% (Weisberg et al. 2006). Both chondrules and matrix are dominated by olivine and pyroxene.

We calculated thermal conductivities for model compositions of $\mathrm{H}, \mathrm{L}$, and LL chondrites by geometric mean of the relative abundances of olivine $(\mathrm{Ol})$, pyroxene (orthopyroxene $(\mathrm{OPy})+$ clinopyroxene (CPy)), plagioclase, troilite, $\mathrm{Fe}-\mathrm{Ni}$, porosity, and the respective thermal conductivities as follows:

$$
\lambda_{g e o}=\Pi \lambda_{i}^{n_{i}}
$$

where $\lambda_{i}$ is the thermal conductivity of the i-th component and $n_{i}$ its volume fraction with $1=\Sigma n$.

The ratios $\mathrm{Ol} / \mathrm{Py}$ and $\mathrm{OPy} / \mathrm{CPy}$, and the volume percent of Fe-Ni were kept constant within each ordinary chondrite class, while the volume percent of porosity changed. The O1/Py ratio is 1.2, 1.6, and 2.5 for H, L, and LL chondrites, respectively (Van Schmus 1969, McSween et al. 1991). The OPy/CPy ratio is 5.7, 4.0, and 3.5 for H, L, and LL chondrites, respectively (Van Schmus 1969, Yomogida and Matsui 1983). Reported weight percentages in Van Schmus (1969) and Yomogida and Matsui (1983) were converted to volume percentages using the density of each mineral phase in Yomogida and Matsui (1983).

The volume percent of plagioclase varies only little in ordinary chondrites (Hutchison 2004). In addition, troilite or FeS content is fairly uniform in H, L, and LL chondrites (Hutchison 2004). Thermal conductivities for iron-nickel alloys from Ho et al. (1978) in our model compositions of H, $\mathrm{L}$, and LL chondrites are based on the average metal nickel concentrations of $\mathrm{H}, \mathrm{L}$, and LL chondrites of $10 \%, 14 \%$, and 30\%, respectively (Reisener and Goldstein 2003, Jarosewich 1990). Variables used in our models for different ordinary chondrites are presented in Table 1 . To compare our calculated conductivities of model compositions in ambient and vacuum conditions, we used thermal conductivity of air of $0.024 \mathrm{~W} / \mathrm{m} / \mathrm{K}$ and $3.0 \times 10^{-6} \mathrm{~W} / \mathrm{m} / \mathrm{K}$, respectively.

\subsection{Correction of thermal conductivities measured in ambient air to low pressure equivalents}

The thermal conductivity of a meteorite depends on the conductivity of its mineral constituents, the conductivity of the gas/fluid in its pore space, and the geometry and degree of the porosity. The pressure of gas in the pore space has a strong effect on thermal conductivity (e.g. Fountain and West 1970), which can be explained with regard to the mean free path of molecules in the gas (Fujii and Osako 1973). Since we measured thermal properties in ambient air and Opeil et al. $(2010,2012)$ and Yomogida and Matsui (1983) at significantly lower pressures, we subtracted the effect of air in the pore space from our results in order to get comparable values. Assuming the effective shape of pores is spheroidal, we can calculate the average aspect ratio of pores using the theoretical expression of 
Walsh and Decker (1966). The relation between the effective thermal conductivity at 1 atm $\left(K_{e}\right)$ and the thermal conductivity of the solid $\left(K_{S}\right)$ and fluid in the pores $\left(K_{f}\right)$ is

$$
\frac{K_{s}-K_{e}}{K_{s}-K_{f}}=\frac{p}{3} \frac{1}{K_{f} / K_{e}+\frac{1}{2}(\pi \alpha)},
$$

where $p$ and $\alpha$ are the porosity and the aspect ratio of the pores, respectively (Fujii and Osako 1973, Walsh and Decker 1966). Considering vacuum and lower temperature conditions, $K_{f}$ can be neglected, and the effective thermal conductivity in vacuum $\left(K_{v}\right)$ is then

$$
\frac{K_{s}-K_{v}}{K_{s}}=\frac{p}{3} \frac{2}{\pi \alpha}
$$

(Walsh and Decker 1966, Fujii and Osako 1973). We calculated the effective conductivity in vacuum from the model composition curves that corresponds to the porosity of our samples, and used Eq. 5 to estimate a value of the aspect ratio of pores of our samples. The aspect ratio of pores increases polynomially with increasing porosity (Fig. 1), and thermal conductivity is highly sensitive to the aspect ratio of pores. Using the values of measured conductivity in ambient air, thermal conductivity of ambient air, porosity, and acquired aspect ratio of pores we can calculate the thermal conductivity of the solid and the effective thermal conductivity of our samples under vacuum conditions (Eqs. 4 and 5). Specific heat capacity of our samples is calculated using the measured thermal conductivity, diffusivity, and density in ambient air. Thermal diffusivities of our samples under vacuum conditions are calculated using the thermal conductivity under vacuum conditions, bulk density and specific heat capacity (Eq. 2). The calculated aspect ratio of pores, thermal diffusivity, and thermal conductivity at low pressure are reported in Table 2.

\section{Results}

The results of this study and literature data are compiled in Table 2. Error margins are reported for our data and when given in other studies. According to our data, thermal conductivity of chondrites is $0.22-3.10 \mathrm{~W} / \mathrm{m} / \mathrm{K}$. In the case of finds, the range is $0.72-3.10 \mathrm{~W} / \mathrm{m} / \mathrm{K}$, and in the case of falls $0.22-2.37 \mathrm{~W} / \mathrm{m} / \mathrm{K}$. Thermal diffusivities are $0.30-1.09 \mathrm{~mm}^{2} / \mathrm{s}$ and $0.05-0.72 \mathrm{~mm}^{2} / \mathrm{s}$ for chondrite finds and falls, respectively. It is important to note that Table 2 contains thermal conductivities measured at $200 \mathrm{~K}$ and $300 \mathrm{~K}$, and that the results are marginally higher $(<0.4 \mathrm{~W} / \mathrm{m} / \mathrm{K})$ for ordinary chondrites at $300 \mathrm{~K}$ (Ostrowski and Bryson 2019). Calculated average thermal conductivities and porosities for chondrite classes from data in Table 2 representing $300 \mathrm{~K}$ and vacuum conditions are presented in Table 3.

Thermal conductivities and porosities of all meteorites, including both falls and finds, in Table 2 are presented in a histogram in Fig. 2. In this study, the porosity of the measured chondrites is $2.4-$ $19.7 \%$ for finds and $5.2-22.6 \%$ for falls. Figs. 3 and 4 show the overlap among ordinary chondrites' thermal conductivities.

Our data and previously published thermal conductivity values and porosities for chondrite falls are presented in Fig. 5. We found a linear correlation between thermal conductivity and porosity with R-squared value of 0.88 for chondrite falls in our results (Fig. 5). The correlation for chondrite falls in all data is weaker with R-squared value of 0.61. Outliers, E chondrites Abee (EH4, breccia, see section 4, Data) and Pillistfer (EL6), are excluded from the correlation. In addition, ordinary chondrite Alfianello (L6) is excluded because of the measurement uncertainty due to fusion crust present on the measurement surface. Some of the chondrites in this study have two results measured in orthogonal directions, and the correlation contains their average value. 
We observed a linear relationship between thermal conductivity and bulk density over the range of different classes of chondrite falls with R-squared value of 0.64 and 0.62 for our data and all data, respectively (Fig. 6). Chondrites Abee, Pillistfer, Cold Bokkeveld, and Alfianello are not included in the correlation. Fig. 7 shows the correlation between thermal diffusivity and porosity of falls in our results and all the data with R-squared values of 0.85 and 0.70 , respectively. Abee and Alfianello are excluded from the correlation.

Geometric mean models for model compositions of H, L, and LL chondrites are presented in Figs. 8 and 9. Fig. 10 illustrates the effect of varying porosity and metal content at $1 \mathrm{~atm}$, when the ratio of olivine is $1: 1$, and thermal conductivities are calculated for different theoretical compositions of meteorites. Fig. 11 illustrates how thermal conductivities and porosities in Table 2 fit to the calculated thermal conductivities for model compositions of ordinary chondrite classes.

\section{Discussion}

Data. Our results are within the range $(0.4-5.5 \mathrm{~W} / \mathrm{m} / \mathrm{K})$ of thermal conductivities of chondrites previously reported by Yomogida and Matsui (1983), Opeil et al. (2010), and Opeil et al. (2012). However, our results do not extend to the values above $3.1 \mathrm{~W} / \mathrm{m} / \mathrm{K}$. Thermal conductivities of enstatite chondrites Abee (Opeil et al. 2010) and Pillistfer (Opeil et al. 2012) are much higher (>5 $\mathrm{W} / \mathrm{m} / \mathrm{K}$ ) than the highest conductivities measured in this study for McKinney (L4) and Ransom (H4). In Opeil et al. (2010), the reported, directly measured, thermal conductivity of Abee at room temperature is close to that of olivine and enstatite (c. $5 \mathrm{~W} / \mathrm{m} / \mathrm{K}$ ). Thermal conductivity of the sample of Abee measured in this study is $2.33 \mathrm{~W} / \mathrm{m} / \mathrm{K}$ at $1 \mathrm{~atm}(0.63 \mathrm{~W} / \mathrm{m} / \mathrm{K}$ at low pressure), which is significantly lower. However, Abee is a breccia consisting of both metal-rich and metal poor clasts that may be very large in size (Sears et al. 1983), and the size of these clasts may exceed the size of the sample that Opeil et al. (2010) measured. The sample measured in this study contains clasts that are several centimeters in size. Jarosewich (1990) reported enstatite chondrites being commonly heterogeneous on scales larger than $10 \mathrm{~g}$ (i.e. about $1.4 \mathrm{~cm}$ ). These observations and the difference in measured conductivities of Abee in different studies indicate that our result may not sample the entire meteorite or the enstatite parent body.

In addition, Opeil et al. (2010) measured a porosity of 3.0\% for their sample of Abee, while the determined porosity for the sample of Abee in this study is remarkably higher, 22.6\%. Especially, the difference in measured grain densities is high, which may reflect the amount of metallic Fe-Ni in the samples. It is possible that the large clasts of our sample of Abee are metal-rich, since the measured grain density is notably high $\left(4.4 \mathrm{~g} / \mathrm{cm}^{3}\right)$ whereas the grain density in Opeil et al. (2010) is lower (3.6 $\left.\mathrm{g} / \mathrm{cm}^{3}\right)$.

Iron components in chondrites are dimensionally heterogeneously distributed and have high thermal conductivity which may result in differences of the average conductivity of the sample and between samples of varying size of the same meteorite. Since the reported thermal conductivity is a mean value in this study, the lower thermal conductivity of our sample of Abee may be explained by the thin scanning line whose path encountered mostly silicate material or metal-poor clasts. Indeed, the difference of the minimum and maximum thermal conductivity recorded in the measurement path is notably large, and the value of inhomogeneity coefficient is high. In addition, the instrument recorded a high value of coefficient of variation. Hence, there is very large heterogeneity and possibly anisotropy in conductivity in our sample of Abee. It seems that the difference in grain densities between our sample of Abee and the sample in Opeil et al. (2010) is due to Fe-Ni content whereas the difference in thermal conductivity may be attributed to porosity. Plots in Fig. 10 agree with this notion.

Thermal conductivity evidently depends on the quantity of iron in the meteorite. Bearing in mind the different iron contents in H, L, and LL chondrites, one may assume that $\mathrm{H}$ chondrites have the highest average thermal conductivity and LL chondrites the lowest. In the compiled data, this trend 
persists within the different classes of chondrites (Fig. 4 and Table 3). However, in our data this trend is not as obvious but slightly obscured (Fig. 3 and Table 3). Consolmagno et al. (2008) report average porosities of $7.0 \%, 5.6 \%$, and $8.2 \%$ for $\mathrm{H}$ chondrite falls, $\mathrm{L}$ chondrite falls, and LL chondrite falls, respectively. In our results, $\mathrm{L}$ chondrites have the lowest average porosity of these classes and the highest average thermal conductivity of ordinary chondrites (Fig. 3 and Table 3).

Thermal diffusivities and conductivities are very different and scattered even among samples of the same chemical and petrologic type (Figs. 3 and 4), which suggests that the physical structure of the stony meteorites strongly affects the thermal conductivity (Ostrowski and Bryson 2019). This is observed for both falls and finds of H, L, and LL chondrites in this study. L6 chondrites have the largest variation in thermal conductivity in our data (Fig. 3), and in the compiled data, the largest variation is found within $\mathrm{H} 5$ chondrites (Fig. 4). Although meteorites with different petrologic types have nearly the same chemical composition, there are only few common features among them. This raises a question whether the sample sizes of 4-10 cm are too small to represent the whole meteorite.

Measurements of thermal properties of different samples of the same meteorite demonstrate the effect of heterogeneity in the cm-scale. For example, we measured a difference of $0.41 \mathrm{~W} / \mathrm{m} / \mathrm{K}$ in conductivity for different samples of Arcadia (LL6). In addition, we measured 21 ordinary chondrites in two orthogonal directions, and found significant differences for Ferguson Switch (H5, $\Delta \mathrm{k}=0.45$ $\mathrm{W} / \mathrm{m} / \mathrm{K}$ ), McKinney (L4, $\Delta \mathrm{k}=0.27 \mathrm{~W} / \mathrm{m} / \mathrm{K}$ ), and Bath Furnace (L6, $\Delta \mathrm{k}=0.21 \mathrm{~W} / \mathrm{m} / \mathrm{K}$ ). Opeil et al. (2012) reported differences in thermal conductivity of Bath Furnace and Holbrook when measured in two orthogonal directions and in different samples of the same meteorite. While we observed a difference in thermal conductivity of Bath Furnace when measured in two orthogonal directions, there was no significance difference in Holbrook when measured in two directions. As Opeil et al. (2012) noted, the differences are greater than any measurement error, and must portray structural differences in the conductivity within the samples, including significant anisotropy. Thus, the relationship between thermal conductivity and porosity or mineralogy cannot be simple, as the conductivity changes with the orientation of cracks and pores (Opeil et al. 2012).

The results of Yomogida and Matsui (1983) imply that thermal conductivity decreases when porosity increases. Opeil et al. (2012) showed that, in general, thermal conductivity is linearly inversely proportional to porosity, despite the fact that the relationship does not include the anisotropic effects of shock-induced cracks. However, there are samples, e.g. L6 chondrite Kunashak (Yomogida and Matsui 1983) and L5 Sevrukovo (this study), that are inconsistent with this tendency. Our data agree well with the linear inverse relationship between thermal conductivity and porosity at room temperature (Fig. 5). However, the correlation in all the data is weaker. Recall that our data are the corrected thermal conductivities which are sensitive to the calculated aspect ratio of pores. It is possible that the correlation in all the data would be stronger if our data were measured in vacuum conditions. In addition, data dispersion may be due to different measurement methods. Additionally, samples measured in this study are large in size and show heterogeneity in $\mathrm{cm}$-scale, which consequently makes the range of the dataset larger compared to the range of a dataset with similar sized samples.

Szurgot (2011) observed a linear relationship between thermal conductivity and bulk density over the range of stony meteorites, stony iron meteorites and iron meteorites. Our data, as well as all the data, agree reasonably well with this trend within the various classes of stony meteorite falls (Fig. 6). In addition, our data and all the data agree well with the relationship between thermal diffusivity and porosity observed by Yomogida and Matsui (1983) (Fig. 7).

Theoretical modeling of conductivity. Our theoretical models give only rough assumptions of the thermal conductivities with the main aim to describe the effects of porosity and metal content on thermal conductivity. However, geometric mean model demonstrates a feasible agreement between calculated and measured bulk thermal conductivity (Fuchs et al. 2013). Geometric models in Fig. 10 for different theoretical compositions of meteorites show, for example, that as metal content increases from $10 \%$ to $20 \%$, thermal conductivity at porosity of $25 \%$ increases $0.35 \mathrm{~W} / \mathrm{m} / \mathrm{K}$. In comparison, if 
porosity increases from $10 \%$ to $20 \%$, thermal conductivity at metal content of $25 \%$ decreases 1.72 $\mathrm{W} / \mathrm{m} / \mathrm{K}$. At porosity of $2 \%$, the thermal conductivity increases $1.17 \mathrm{~W} / \mathrm{m} / \mathrm{K}$ when metal content increases from $10 \%$ to $20 \%$, and at metal content of $2 \%$, conductivity decreases $1.02 \mathrm{~W} / \mathrm{m} / \mathrm{K}$ when porosity increases from $10 \%$ to $20 \%$. In summary, if porosity remains the same, especially for low porosity values, and metal content increases from $2 \%$ to $25 \%$ the change in thermal conductivity is smaller compared to the change in conductivity when metal content remains the same and porosity increases from $2 \%$ to $25 \%$.

The model results indicate that, for each type of ordinary chondrites, thermal conductivity decreases as porosity increases (Fig. 11). Thus, decreasing porosity facilitates the development of more thermal paths. The decrease in thermal conductivity is more rapid when porosity is lower than about $10 \%$. Especially for $\mathrm{H}$ chondrites, the thermal conductivity decreases more rapidly at lower porosities and thermal conductivity reaches the highest value of c. $4.4 \mathrm{~W} / \mathrm{m} / \mathrm{K}$ at zero porosity, which is nearly four times larger compared to thermal conductivity at porosity of $25 \%$ (Fig. 9). The decrease of thermal conductivity is nearly linear at low porosities for H, L, and LL chondrites (Fig. 11). Thermal conductivity of $\mathrm{H}$ chondrites decreases the most when porosity increases from $2 \%$ to $25 \%$ and thermal conductivity of LL chondrites the least. In comparison to H chondrites, the decrease of thermal conductivity for LL chondrites with incorporated porosity is not as significant, and the highest value of conductivity is c. $3.9 \mathrm{~W} / \mathrm{m} / \mathrm{K}$ at zero porosity. For the same porosity, the thermal conductivities of different ordinary chondrites always act in accordance with the order of $H>L>L L$ due to the composition of the ordinary chondrites.

Measured conductivities and porosities in Opeil et al. (2010, 2012) and Yomogida and Matsui (1983) fit reasonably well to the calculated thermal conductivity curves for model compositions of ordinary chondrites in Fig. 11. Recall that their measurements were conducted under vacuum and our results are obtained at $1 \mathrm{~atm}$. Thus, air in the pore space of our samples has thermal conductivity of c. $0.024 \mathrm{~W} / \mathrm{m} / \mathrm{K}$, which is considerably higher compared to conductivity of air in vacuum, and this leads to higher conductivities when measured in room conditions. However, our results corrected to low pressure fit moderately well to the curves. Aberration of the calculated curves from the measured results may be due to the simplified model, which only considers the contents of iron-nickel, olivine, pyroxene, plagioclase, and troilite with varying porosity. The composition of olivine, and thus the estimated thermal conductivity of olivine, was constant in the calculations for different ordinary chondrite classes. It is important to note that the geometry of the pore space in our samples is not known and the calculated values of the aspect ratio of pores and conductivity in vacuum based on the model composition curves are suggestive. There is definitely a need to investigate the geometry of the pore space more deeply.

Effect of macro porosity and structure. The heterogeneity and isotropic nature of asteroids derive from macro porosity. Large fractures and voids are probably caused by impacts and represent the zones of structural weakness along which meteorites break apart during impacts. These features are large on the scale of meteorites. Creation of cracks is possible with small change of porosity, and impacts do not necessarily affect the sample porosity (Yomogida and Matsui 1983). It has been shown that porosity of shocked and unshocked chondrites is nearly the same (Anders 1964, Consolmagno et al. 2008). Thus, impacts affect macro porosity, but the effect on micro porosity of meteorites may not be significant, and meteorites' thermal properties may not be altered significantly due to the impact history and thus represent thermal properties of material within asteroids. However, it is likely that the macro porosities of asteroids are considerable, since their bulk densities appear to fall well behind the grain density of their probable meteorite analogues. This indicates asteroids have also lower thermal conductivities compared to their meteorite analogues. Thus, modeling the thermal evolution of an asteroid relies heavily on assumptions of the internal structure of asteroids and how to use the thermal data obtained from meteorites.

The basic material of ordinary chondrite parent bodies is strong since it contains welded silicates and metal providing a fortifying structural mesh, which is often adjoined if the ordinary chondrite has 
experienced re-melting and metamorphic processing (Scheeres et al. 2015). Ordinary chondrites often contain large zones of pre-existing weakness. Although the nature of fracturing varies, chondrites generally display random fractures notwithstanding the meteorite texture (Bryson et al. 2015). In addition, some chondrites exhibit a distinct network of fractures (Bryson et al. 2015). Further research on the geometry of pore space in meteorites would be an interesting extension considering thermal properties of meteorites.

Since our samples are of several centimeters size, some of them exhibit cracks to varying extent causing heterogeneity and possibly anisotropy. Thus, larger heterogeneity is expected compared to millimeter-sized samples in previous studies. However, it has been observed in non-shocked ordinary chondrites that cracks are the minor contribution to porosity, with around two-thirds of porosity coming from inter-granular voids (Sasso et al. 2009). Also, Consolmagno et al. (2008) reported that only a very weak correlation between porosity and shock state has been found. Considering the complex impact history of asteroids and assuming the random orientation of cracks, an average correlation between porosity and thermal conductivity should feasibly describe the typical conductivity within an asteroid (Opeil et al. 2012).

In studies by Consolmagno and Britt (1998), Flynn et al. (1999), and Wilkison et al. (2003), no correlation between porosity and petrologic grade was found indicating porosity is not dependent on the heating process. It is expected that metamorphism alters porosity and pores may be generated after metamorphism. Considering the data in this study, the porosity of $\mathrm{H}$ chondrites somewhat decreases with increasing metamorphic temperature. This suggests raising temperature stimulates compaction and recrystallization. However, there are significant variations in porosity within the same petrologic types. On the other hand, the porosity of L chondrites appears to increase with increasing metamorphic temperature. Since there is no obvious correlation between petrologic type and porosity, it is feasible that impact shocking has reworked the material.

Effect of weathering. In analyzing meteorites, especially meteorite finds, weathering effects, such as metal oxidation, and the degree of weathering must be assessed, since weathering affects the meteorite's primordial composition. Considering ordinary chondrites, Gibson and Bogart (1978) and Bland et al. (1998) recognized a depletion in $\mathrm{Si}$ and $\mathrm{Mg}$ with increasing weathering, while the elemental concentration of Fe was not significantly altered (Bland et al. 2006). Al-Kathiri et al. (2005) observed mobilization of $\mathrm{Ni}$ and $\mathrm{Co}$ in connection with breakdown of Fe-Ni metal. Fe-Ni metal, troilite, and mafic silicates expose ordinary chondrites to rusting, which causes the most evident weathering products on meteorites. As metals oxidize, their thermal conductivities decrease, and thus the conductivity potential of meteorites will weaken. Ordinary chondrite falls have quite large porosities of 11-15\% (Wasson 1974) with an average range of 8-9.5\% (Flynn et al. 2018). Ordinary chondrite finds have porosities of 2.8-5.8\% (Macke 2010). Oxidation of metal induces grain volume expansion (Buddhue 1957), and thus, porosity may reduce (Bland et al. 2006). This translates to falls having higher porosities than finds. There are many similarities between ordinary and carbonaceous chondrite weathering. It is evident that meteorite finds are weathered to varying degrees. However, falls, especially carbonaceous chondrite falls, are also vulnerable to alteration by terrestrial environment because of e.g. a large proportion of fine-grained matrix and abundance of volatile elements (Bland et al. 2006). For example, Abreu and Brearley (2005) have concluded that the veins in CV3 chondrite fall Vigarano are terrestrial in origin.

Bland et al. (1996a, b, 1998, 2000) examined a quantitative index of alteration for ordinary chondrites based on applying Mössbauer spectroscopy to determine the relative abundances of $\mathrm{Fe}^{\mathrm{O}}$ in metal, $\mathrm{Fe}^{2+}$ in sulfide and silicate, and $\mathrm{Fe}^{3+}$ in weathering products (Hutchison 2004). The amounts of oxidized $\mathrm{Fe}$ in weathered ordinary chondrites can be linked with particular outset compositions since the amounts of $\mathrm{Fe}^{\mathrm{O}}$ and $\mathrm{Fe}^{2+}$ are well known in ordinary chondrite falls (Hutchison 2004). A mineralogic alteration index (MAI) is based on studies to qualify (McSween 1979) and quantify the extent of alteration in CM falls (Browning et al. 1996). There is a strong positive correlation between MAI and the year of fall, and the more altered a meteorite is the older the fall is, but it is not clear if 
MAI indicates terrestrial or pre-terrestrial alteration (Bland et al. 2006). Although MAI is established by studies on carbonaceous chondrites, it may have significance on ordinary chondrites given the similarities between their weathering. Many of the falls measured in this study date back to the nineteenth century, and these assumptions need to be kept in mind when analyzing the data.

\section{Conclusions}

Our results cover almost the entire range of thermal conductivities of chondrites previously reported. On average, enstatite chondrites show much higher conductivities compared to ordinary chondrites. Carbonaceous chondrites have lower metal contents and higher average porosities than ordinary chondrites, and their conductivities fall in the lower end of the range of conductivities of ordinary chondrites. Based on the decreasing metal content in ordinary chondrite classes (H>L $>\mathrm{LL})$, one may expect $\mathrm{H}$ chondrites to have the highest average conductivity and LL chondrites the lowest. This trend shows in the compilation of our results and literature data.

Our results confirm earlier work on the inverse linear relationship between porosity and thermal conductivity of meteorites. We found a reasonable linear correlation between thermal conductivity and bulk density of chondrite falls in addition to inverse relationship between thermal diffusivity and porosity of chondrite falls. Thermal conductivity curves for model compositions of ordinary chondrites calculated by geometric mean fit reasonably well to the measured conductivities and porosities in this study and previous studies.

Measurements of different samples of the same meteorite demonstrate the effect of heterogeneity in the $\mathrm{cm}$-scale. Differences between thermal conductivities of the same sample measured in orthogonal directions indicate porosity may largely govern the conductivity. The differences must portray variation in conductivity with the geometry of the pore space, since they exceed any measurement error.

Thermal diffusivities and conductivities are very different even among samples of the same chemical and petrologic type, which also suggests that the physical structure of the stony meteorites strongly affects the thermal conductivity. Applied hypothetical models of H, L, and LL compositions with varying porosity and metal content indicate that internal structure (i.e. porosity) of the meteorite may affect the thermal conductivity even more compared to the metal content of the meteorite. However, the effects of porosity and metal content cannot be completely separated. The impact history may not have altered the micro porosity of the meteorite, but large enough samples may exhibit random cracks that evidently affect thermal conductivity and cause heterogeneity and possibly anisotropy. Our samples are of several centimeters size, and exhibit cracks in some cases. However, it has been observed that cracks contribute only little to porosity.

Meteorites are primarily composed of minerals that are typical in terrestrial rocks, and models of thermal evolution of asteroids often utilize thermal properties of these minerals to estimate e.g. thermal conductivities. Previous measurements of thermal conductivities of meteorites, as well as the results in this study, show that thermal conductivities of pure minerals comprising the meteorites are substantially higher compared to the measured bulk conductivities of meteorite samples. Thermal properties and porosity of meteorites are intimately coupled and should be studied jointly.

\section{Acknowledgments}

A.-J. Soini is grateful to the Vilho, Yrjö and Kalle Väisälä Foundation of the Finnish Academy of Science and Letters and Nordenskiöld-Samfundet for financial support through research grants. We are thankful to the reviewers for their constructive criticism.

Availability of data. The data that support the findings of this study are openly available in Zenodo at https://doi.org/10.5281/zenodo.3588334. 


\section{References}

Abe S., Mukai T., Hirata N., Barnouin-Jha O. S., Cheng A. F., Demura H., Gaskell R. W., Hashimoto T., Hiraoka K., and Honda T. 2006. Mass and local topography measurements of Itokawa by Hayabusa. Science 312(5778):1344-1347.

Abreu N. M. and Brearley A. J. 2005. Carbonates in Vigarano: Terrestrial, preterrestrial, or both? Meteoritics \& Planetary Science 40:609-625.

Al-Kathiri A., Hofmann B. A., Jull A. J. T., and Gnos E. 2005. Weathering of meteorites from Oman: Correlation of chemical/mineralogical weathering proxies with $14 \mathrm{C}$ terrestrial ages and the influence of soil chemistry. Meteoritics \& Planetary Science 40:1215-1239.

Anders E. 1964. Origin, age and composition of meteorites. Space Science Reviews 3:583-714.

Beech M., Coulson I.M., Nie W., and McCausland P. 2009. The thermal and physical characteristics of the Gao-Guenie (H5) meteorite. Planetary and Space Science 57:764-770.

Bland P. A., Smith T. B., Jull A. J. T., Berry F. J., Bevan A. W. R., Cloudt S., and Pillinger C. T. 1996a. The flux of meteorites to the Earth over the last 50,000 years. Monthly Notices of the Royal Astronomical Society 283:551-565.

Bland P. A., Berry F., Smith T. B., Skinner S., and Pillinger C. T. 1996b. Flux of meteorites to the Earth and weathering in hot desert ordinary chondrite finds. Geochimica et Cosmochimica Acta 60:2053-2059.

Bland P. A., Sexton A., Jull A. J. T., Bevan A. W. R., Berry F. J., Thornley D., Astin T., and Pillinger C. T. 1998. Climate and rock weathering: A study of terrestrial age dated ordinary chondritic meteorites from hot desert regions. Geochimica et Cosmochimica Acta 62:3169-3184.

Bland P. A., Bevan A. W. R., and Jull A. J. T. 2000. Ancient meteorite finds and the Earth surface environment. Quarternary Research 53:131-142.

Bland P. A., Zolensky M. E., Benedix G. K., and Sephton M. A. 2006. Weathering of chondritic meteorites. In Meteorites and the early solar system II, edited by Lauretta D. S. and McSween H. Y. Tucson: University of Arizona Press. 943 p. pp. 853-867.

Britt D. T. and Consolmagno G. J. 2003. Stony meteorite porosities and densities: a review of the data through 2001. Meteoritics \& Planetary Science 38:1161-118.

Britt D. T., Yeomans D., Housen K., and Consolmagno G. 2002. Asteroid density, porosity, and structure. In Asteroids III, edited by Bottke W. F. Jr, Cellino A., Paolicchi P., and Binzel R. P. Tucson: University of Arizona Press. pp. 485-500.

Browning L. B., McSween H. Y. Jr., and Zolensky M. E. 1996. Correlated alteration effects in CM carbonaceous chondrites. Geochimica et Cosmochimica Acta 60:2621-2633.

Bryson K., Ostrowski D. R., and Sears D. W. G. 2015. Meteorite fractures and the behavior of meteoroids in the atmosphere (abstract \#NH11A-1887). AGU Fall Meeting.

Buddhue J. D. 1957. The Oxidation and Weathering of Meteorites. Albuquerque, University of New Mexico Press. 161p.

Butler C. P. and Jenkins R. J. 1963. Thermal properties of meteoritic iron from -150 degrees to 300 degrees celsius. Science 139:486-487.

Clauser C. and Huenges E. 1995. Thermal conductivity of rocks and minerals. Rock physics \& phase relations: a handbook of physical constants, volume 3, edited by Ahrens T. J. Washington (D.C.): American Geophysical Union, cop. pp.105-126. doi: 10.1029/RF003.

Consolmagno G. J. and Britt D. T. 1998. The density and porosity of meteorites from the Vatican collection. Meteoritics \& Planetary Science 33(6):1231-1241.

Consolmagno G. J., Britt D. T., and Macke R. J. 2008. The significance of meteorite density and porosity. Chemie der Erde - Geochemistry 68(1):1-29. 
Debye P., Nernst W., Smoluchowski M., Sommerfeld A., and Lorentz H. 1914. Vorträge über die kinetische Theorie der Materie und der Elektrizität, Berlin: B. G. Teuber, 196 p.

Dodd R. T. 1981. Meteorites: A Petrologic-Chemical Synthesis, New York: Cambridge University Press, 377 p.

Flynn G. J., Moore L. B., and Klöck W. 1999. Density and porosity of stone meteorites: Implications for the density, porosity, cratering, and collisional disruption of asteroids. Icarus 142(1):97-105.

Flynn G. J., Consolmagno G. J., Brown P., and Macke R. J. 2018. Physical properties of the stone meteorites: Implications for the properties of their parent bodies. Chemie der Erde 78:269-298.

Fountain J. A. and West E. A. 1970. Thermal conductivity of particulate basalt as a function of density in simulated lunar and Martian environments. Journal of Geophysical Research 75(20):4063-4069.

Fuchs S., Schütz F., Förster H. J., and Förster A. 2013. Evaluation of common mixing models for calculating bulk thermal conductivity of sedimentary rocks: correction charts and new conversion equations. Geothermics 47:40-52.

Fujii N. and Osako M. 1973. Thermal diffusivity of lunar rocks under atmospheric and vacuum conditions. Earth and Planetary Science Letters 18(1):65-71.

Gibson E. K. Jr. and Bogard D. D. 1978. Chemical alterations of the Holbrook chondrite resulting from terrestrial weathering. Meteoritics 13:277.

Grady M. M. 2000. Catalogue of Meteorites, $5^{\text {th }}$ edition, Cambridge University Press, $696 \mathrm{p}$.

Hashin Z. and Shtrikman S. 1962. A variational approach to the theory of the effective magnetic permeability of multiphase materials. Journal of Applied Physics 33(10):3125-3131. doi:10.1063/1.1728579

Ho C. Y., Ackerman M. W., Wu K. Y., Oh S. G., and Havill T. N. 1978. Thermal conductivity of ten selected binary alloy systems. Journal of Physical and Chemical Reference Data 7(3):959-1178.

Hofmeister A. M., Branlund J. M., and Pertermann M. 2007. Properties of rocks and minerals Thermal conductivity of the Earth. Treatise of Geophysics 2:543-577.

Hofmeister A. M. and Pertermann M. 2008. Thermal diffusivity of clinopyroxenes at elevated temperature. European Journal of Mineralogy 20(4):537-549.

Hutchison R. 2004. Meteorites: A Petrologic, Chemical and Isotopic Synthesis, $1^{\text {st }}$ edition, New York: Cambridge University Press, 506 p.

Jarosewich E. 1990. Chemical analysis of meteorites: A compilation of stony and iron meteorite analyses. Meteoritics 25:323-337.

Kohout T. 2009. Physical properties of meteorites and their role in planetology. Ph.D. thesis, University of Helsinki, Department of physics, Helsinki, Finland.

Macke R. J. 2010. Survey of Meteorite Physical Properties: Density, Porosity and Magnetic Susceptibility. Ph. D. Thesis. University of Florida, Department of Physics, Orlando, Florida, United States of America.

Macke R. J., Kent J. J., Kiefer W. S., and Britt D. T. 2015. 3D-Laser-Scanning Technique Applied to Bulk Density Measurements of Apollo Lunar Samples (abstract \#1716). 46 ${ }^{\text {th }}$ Lunar and Planetary Science Conference.

Matsui T. and Osako M. 1979. Thermal property measurement of Yamato meteorites. Memoirs of National Institute of Polar Research Special Issue 15:243-252.

McSween H. Y. 1979. Alteration in CM carbonaceous chondrites inferred from modal and chemical variations in matrix. Geochimica et Cosmochimica Acta 43:1761-1770.

McSween H. Y., Bennett M. E., and Jarosewich E. 1991. The mineralogy of ordinary chondrites and implications for asteroid spectrophotometry. Icarus 90(1):107-116.

Michel P. 2014. Formation and physical properties of asteroids. Elements 10(1):19-24. 
Opeil C. P., Consolmagno G. J., and Britt D. T. 2010. The thermal conductivity of meteorites: New measurements and analysis. Icarus 208(1):449-454.

Opeil Sj C. P., Consolmagno Sj G. J., Safarik D. J., and Britt D. T. 2012. Stony meteorite thermal properties and their relationship with meteorite chemical and physical states. Meteoritics \& Planetary Science 47(3):319-329.

Ostrowski D. R. and Bryson K. L. 2017. Meteorite Physical Properties Related to Asteroid Atmospheric Entry (abstract \#2669). $48^{\text {th }}$ Lunar and Planetary Science Conference.

Ostrowski D. R. and Bryson K. L. 2019. The physical properties of meteorites. Planetary and Space Science 165:148-178. doi:10.1016/j.pss.2018.11.003.

Popov Y. A., Berezin V. V., Semionov V. G., and Korosteliov V. M. 1985. Complex detailed investigations of the thermal properties of rocks on the basis of a moving point source. Izv Phys Solid Earth 21(1):64-70.

Popov Y. A., Pribnow D. F., Sass J. H., Williams C. F., and Burkhardt H. 1999. Characterization of rock thermal conductivity by high-resolution optical scanning. Geothermics 28(2):253276.

Reisener R. J. and Goldstein J. I. 2003. Ordinary chondrite metallography: Part 1. Fe-Ni taenite cooling experiments. Meteoritics \& Planetary Science 38(11):1669-1678.

Sasso M. R., Macke R. J., Boesenberg J. S., Britt D. T., Rivers M. L., Ebel D. S., and Friedrich J. M. 2009. Incompletely compacted equilibrated ordinary chondrites. Meteoritics \& Planetary Science 44:1743-1753.

Scheeres D. J., Britt D., Carry B., and Holsapple K. A. 2015. Asteroid interiors and morphology. In Asteroids IV, edited by Michel P., DeMeo F. E., and Bottke W. F. Tucson: University of Arizona Press. pp. 745-766.

Sears D. W., Kallemeyn G. W., and Wasson J. T. 1983. Composition and origin of clasts and inclusions in the Abee enstatite chondrite breccia. Earth and Planetary Science Letters 62:180-192.

[dataset] Soini A.-J., Kukkonen I. T., Kohout T., Luttinen A. 2019, Measurement data used in "Thermal and porosity properties of meteorites: A compilation of published data and new measurements". Zenodo. http://doi.org/10.5281/zenodo.3588334.

Szurgot M. 2011. Thermal conductivity of meteorites (abstract \#5074). Meteoritics \& Planetary Science 46(s1):A230. doi:10.1111/j.1945-5100.2011.01241.x

Szurgot M. and Wojtatowicz T. W. 2011. Thermal diffusivity of meteorites (abstract \#5036). Meteoritics \& Planetary Science 46(s1):A230.

Szurgot M., Rozniakowski K., Wojtatowicz T. W., and Polanski K. 2008. Investigation of microstructure and thermophysical properties of Morasko iron meteorites. Crystal Research and Technology 43:921-930.

Szurgot M., Wach R.A., and Przylibski T.A. 2012. Thermophysical properties of the Sołtmany meteorite. Meteorites 2:53-65.

Szurgot M., Wach R.A., and Matusiak M. 2014. Thermophysical properties of NWA 4560 chondrite (abstract \#5007). Meteoritics \& Planetary Science 49:A388.

Vernazza P., Zanda B., Nakamura T., Scott E., and Russell S. 2015. The formation and evolution of ordinary chondrite parent bodies. In Asteroids IV, edited by Michel P., DeMeo F. E., and Bottke W. F. Tucson: University of Arizona Press. pp. 617-634. doi: 10.2458/azu_uapress_9780816532131-ch032.

Van Schmus W. R. 1969. The mineralogy and petrology of chondritic meteorites. Earth-Science Reviews 5(3):145-184.

Wach R.A., Szurgot M., and Matusiak M. 2014. Thermal properties of Kilabo chondrite (abstract \#5010). Meteoritics \& Planetary Science 49:A423.

Walsh J. B. and Decker E. R. 1966. Effect of pressure and saturating fluid on the thermal conductivity of compact rock. Journal of Geophysical Research 71(12):3053-3061. 
Wasson J. T. 1974. Meteorites: Classification and Properties. New York: Springer-Verlag. 316 p.

Weibull W. A. 1951. A statistical distribution function of wide applicability. Journal of Applied Mechanics 18:293-297.

Weisberg M. K., McCoy T. J., and Krot A. N. 2006. Systematics and evaluation of meteorite classification. In Meteorites and the early solar system II, edited by Lauretta D. S. and McSween H. Y. Tucson: University of Arizona Press. 943 p. pp. 19-52.

Wilkison S. L., McCoy T. J., McCamant J. E., Robinson M. S., and Britt D. T. 2003. Porosity and density of ordinary chondrites: Clues to the formation of friable and porous ordinary chondrites. Meteoritics \& Planetary Science 38(10):1533-1546.

Wood J. A. 1963. Physics and chemistry of meteorites. In The Moon Meteorites and Comets, edited by Kuiper G. P. and Middlehurts B. Chicago: The University of Chicago Press. pp. 337401.

Yeomans D. K., Barriot J. P., Dunham D. W., Farquhar R. W., Giorgini J. D., Helfrich C. E., Konopliv A. S., McAdams J. V., and Miller J. K. 1997. Estimating the mass of asteroid 253 Mathilde from tracking data during the NEAR flyby. Science 278(5346):2106-2109.

Yomogida K. and Matsui T. 1983. Physical properties of ordinary chondrites. Journal of Geophysical Research: Solid Earth 88(B11):9513-9533. 
Table I. Variables in geometric mean models in this study for $H, L$, and $L L$ chondrites.

\begin{tabular}{|c|c|c|c|c|c|c|}
\hline \multirow[b]{2}{*}{ Mineral } & \multicolumn{2}{|c|}{ H chondrites } & \multicolumn{2}{|c|}{ L chondrites } & \multicolumn{2}{|c|}{ LL chondrites } \\
\hline & $\begin{array}{l}\text { Thermal } \\
\text { conductivity } \\
(\mathrm{W} / \mathrm{m} / \mathrm{K})\end{array}$ & Vol\% & $\begin{array}{l}\text { Thermal } \\
\text { conductivity } \\
(\mathrm{W} / \mathrm{m} / \mathrm{K})\end{array}$ & Vol\% & $\begin{array}{l}\text { Thermal } \\
\text { conductivity } \\
(\mathrm{W} / \mathrm{m} / \mathrm{K})\end{array}$ & Vol\% \\
\hline Olivine & $4.3^{a}$ & varying & $4.3^{\mathrm{a}}$ & varying & $4.3^{a}$ & varying \\
\hline Orthopyroxene & $3.9^{a}$ & varying & $3.9^{a}$ & varying & $3.9^{a}$ & varying \\
\hline Clinopyroxene & $4.6^{a}$ & varying & $4.6^{a}$ & varying & $4.6^{a}$ & varying \\
\hline Plagioclase & $1.9^{a}$ & $10^{\mathrm{b}}$ & $1.9^{\mathrm{a}}$ & $10^{\mathrm{b}}$ & $1.9^{a}$ & $10^{\mathrm{b}}$ \\
\hline Troilite & $4.6^{a}$ & $3.5^{b}$ & $4.6^{a}$ & $3.5^{b}$ & $4.6^{a}$ & $3.5^{b}$ \\
\hline Fe-Ni metal & $28.1^{\mathrm{c}}$ & $8.4^{d}$ & $24.8^{c}$ & $4.1^{d}$ & $14.6^{c}$ & $2.0^{d}$ \\
\hline
\end{tabular}

a Yomogida and Matsui (1983)

b Van Schmus (1969)

c Ho et al. (1978)

d Vernazza et al. (2015) 
Table II. Thermal properties, densities and porosities of meteorites in this study and literature data.

\begin{tabular}{|c|c|c|c|c|c|c|c|c|c|c|c|c|c|c|}
\hline Meteorite & Class & Fall & $\begin{array}{l}\text { Weathering } \\
\text { grade** }\end{array}$ & $\begin{array}{l}\text { Bulk } \\
\text { density } \\
\left(\mathrm{g} / \mathrm{cm}^{3}\right)\end{array}$ & $\begin{array}{l}\text { Grain } \\
\text { density } \\
\left(\mathrm{g} / \mathrm{cm}^{3}\right)\end{array}$ & Porosity (\%) & $\begin{array}{l}\text { Thermal } \\
\text { diffusivity } \\
\left(\mathrm{mm}^{2} / \mathrm{s}\right)\end{array}$ & $\begin{array}{l}\text { Corrected } \\
\text { thermal } \\
\text { diffusivity } \\
\left(1.33 \times 10^{-4}\right. \\
\mathrm{Pa})\left(\mathrm{mm}^{2} / \mathrm{s}\right) \\
\end{array}$ & $\begin{array}{l}\text { Thermal } \\
\text { conductivity } \\
\text { (W/m/K) }\end{array}$ & $\begin{array}{l}\text { Aspect } \\
\text { ratio of } \\
\text { pores }\end{array}$ & $\begin{array}{l}\text { Corrected } \\
\text { thermal } \\
\text { conductivity } \\
\left(1.33 \times 10^{-4}\right. \\
\mathrm{Pa})(\mathrm{W} / \mathrm{m} / \mathrm{K}) \\
\end{array}$ & $\begin{array}{l}\text { Specific } \\
\text { heat } \\
\text { capacity } \\
(\mathrm{J} / \mathrm{kgK})\end{array}$ & Temp. (K) & Notes \\
\hline \multicolumn{15}{|c|}{ Soini et al. (this study) } \\
\hline Kainsaz & $\mathrm{CO} .2$ & Fall & & 3.2 & 3.4 & $7.4 \pm 0.6$ & 0.94 & 0.68 & $2.55 \pm 0.06^{\mathrm{a}}$ & 0.024 & 1.85 & $853^{d}$ & 296 & \\
\hline Allende & CV3 & Fall & & 2.9 & 3.7 & $21.7 \pm 0.5$ & 0.45 & 0.08 & $1.21 \pm 0.01^{\mathrm{a}}$ & 0.048 & 0.22 & $925^{d}$ & 296 & \\
\hline Allende* & CV3 & Fall & & 2.9 & 3.7 & $21.7 \pm 0.5$ & 0.35 & 0.06 & $1.21 \pm 0.02^{\mathrm{a}}$ & 0.048 & 0.22 & $1189^{d}$ & 296 & \\
\hline Abee & EH4 & Fall & & 3.4 & 4.4 & $22.6 \pm 1.4$ & 1.39 & 0.37 & $2.33 \pm 0.09^{a}$ & 0.050 & 0.63 & $491^{d}$ & 296 & \\
\hline Metsäkylä & $\mathrm{H} 4$ & Find & & 3.2 & 3.8 & $15.8 \pm 1.9$ & 0.77 & 0.35 & $2.43 \pm 0.07^{a}$ & 0.037 & 1.10 & $977^{d}$ & 296 & \\
\hline Orimattila & $\mathrm{H} 4$ & Find & & 3.4 & 3.6 & $3.5 \pm 1.0$ & 1.18 & 1.02 & $2.48 \pm 0.05^{\mathrm{a}}$ & 0.019 & 2.14 & $614^{\mathrm{d}}$ & 296 & 1 \\
\hline Orimattila* & $\mathrm{H} 4$ & Find & & 3.4 & 3.6 & $3.5 \pm 1.0$ & 1.06 & 0.92 & $2.57 \pm 0.16^{\mathrm{a}}$ & 0.019 & 2.23 & $711^{d}$ & 296 & 1 \\
\hline Ransom & $\mathrm{H} 4$ & Find & & 3.6 & & $6.1 \pm 0.7$ & 1.33 & 1.09 & $3.64 \pm 0.12^{\mathrm{a}}$ & 0.022 & 2.99 & $761^{d}$ & 296 & 1 \\
\hline Ransom* & $\mathrm{H} 4$ & Find & & 3.6 & & $6.1 \pm 0.7$ & 1.09 & 0.89 & $3.75 \pm 0.13^{\mathrm{a}}$ & 0.022 & 3.09 & $959^{d}$ & 296 & 1 \\
\hline Seneca & $\mathrm{H} 4$ & Find & & 3.1 & 3.9 & $19.7 \pm 1.1$ & 0.87 & 0.30 & $2.41 \pm 0.16^{a}$ & 0.045 & 0.83 & $897^{d}$ & 296 & \\
\hline Seneca* & $\mathrm{H} 4$ & Find & & 3.1 & 3.9 & $19.7 \pm 1.1$ & 0.96 & 0.35 & $2.69 \pm 0.06^{\mathrm{a}}$ & 0.045 & 0.99 & $908^{d}$ & 296 & \\
\hline Cope & H5 & Find & & 3.4 & 3.6 & $7.7 \pm 0.9$ & 0.96 & 0.70 & $2.70 \pm 0.07^{\mathrm{a}}$ & 0.025 & 1.96 & $843^{d}$ & 296 & \\
\hline Cope* & H5 & Find & & 3.4 & 3.6 & $7.7 \pm 0.9$ & 0.96 & 0.70 & $2.79 \pm 0.16^{\mathrm{a}}$ & 0.025 & 2.05 & $871^{d}$ & 296 & \\
\hline Covert & H5 & Find & & 3.2 & 3.6 & $12.6 \pm 1.0$ & 0.93 & 0.53 & $2.63 \pm 0.06^{\mathrm{a}}$ & 0.032 & 1.49 & $896^{d}$ & 296 & \\
\hline Covert* & H5 & Find & & 3.2 & 3.6 & $12.6 \pm 1.0$ & 0.93 & 0.52 & $2.58 \pm 0.14^{a}$ & 0.032 & 1.46 & $880^{d}$ & 296 & \\
\hline Ferguson Switch & H5 & Find & & 3.3 & 3.7 & $9.3 \pm 1.0$ & 0.99 & 0.67 & $2.72 \pm 0.13^{\mathrm{a}}$ & 0.027 & 1.85 & $829^{d}$ & 296 & \\
\hline Ferguson Switch* & H5 & Find & & 3.3 & 3.7 & $9.3 \pm 1.0$ & 1.09 & 0.77 & $3.25 \pm 0.29$ & 0.027 & 2.30 & $899^{d}$ & 296 & \\
\hline Plainview 1 & H5 & Find & & 3.5 & 3.8 & $9.3 \pm 1.0$ & 1.00 & 0.72 & $3.47 \pm 0.14^{\mathrm{a}}$ & 0.027 & 2.51 & $991^{d}$ & 296 & \\
\hline Plainview $1^{*}$ & H5 & Find & & 3.5 & 3.8 & $9.3 \pm 1.0$ & 0.95 & 0.68 & $3.33 \pm 0.09^{a}$ & 0.027 & 2.38 & $1004^{d}$ & 296 & \\
\hline Plainview 2 & H5 & Find & & 3.5 & 3.9 & $10.9 \pm 1.1$ & 1.02 & 0.65 & $2.83 \pm 0.07^{\mathrm{a}}$ & 0.029 & 1.80 & $803^{d}$ & 296 & \\
\hline Plainview 2* & H5 & Find & & 3.5 & 3.9 & $10.9 \pm 1.1$ & 1.00 & 0.64 & $2.89 \pm 0.13^{\mathrm{a}}$ & 0.029 & 1.85 & $837^{d}$ & 296 & \\
\hline Slovak & H5 & Find & & 3.4 & 3.8 & $12.3 \pm 1.0$ & 1.35 & 0.79 & $2.72 \pm 0.09^{\mathrm{a}}$ & 0.032 & 1.59 & $600^{d}$ & 296 & \\
\hline Slovak* & H5 & Find & & 3.4 & 3.8 & $12.3 \pm 1.0$ & 1.23 & 0.72 & $2.72 \pm 0.08^{\mathrm{a}}$ & 0.032 & 1.59 & $656^{d}$ & 296 & \\
\hline Travis County & H5 & Find & W3 & 3.3 & 3.9 & $15.8 \pm 1.2$ & 1.29 & 0.51 & $1.83 \pm 0.05^{a}$ & 0.038 & 0.72 & $432^{d}$ & 296 & \\
\hline Cobija & H6 & Find & & 3.4 & 3.8 & $11.2 \pm 1.2$ & 0.82 & 0.53 & $3.12 \pm 0.11^{\mathrm{a}}$ & 0.030 & 2.01 & $1121^{d}$ & 296 & \\
\hline Holbrook & L/LL6 & Fall & & 3.1 & 3.7 & $14.3 \pm 0.6$ & 0.46 & 0.18 & $1.44 \pm 0.07^{a}$ & 0.035 & 0.56 & $1001^{d}$ & 296 & \\
\hline Holbrook* & L/LL6 & Fall & & 3.1 & 3.7 & $14.3 \pm 0.6$ & 0.41 & 0.16 & $1.43 \pm 0.06^{\mathrm{a}}$ & 0.035 & 0.55 & $1106^{d}$ & 296 & \\
\hline Mezö-Madaras & L3.7 & Fall & & 3.3 & 3.5 & $5.2 \pm 1.2$ & 0.88 & 0.72 & $2.89 \pm 0.17^{a}$ & 0.021 & 2.37 & $982^{d}$ & 296 & \\
\hline McKinney & L4 & Find & & 3.5 & 3.6 & $4.7 \pm 0.8$ & 1.14 & 0.97 & $3.32 \pm 0.13^{\mathrm{a}}$ & 0.021 & 2.83 & $843^{d}$ & 296 & \\
\hline McKinney* & L4 & Find & & 3.5 & 3.6 & $4.7 \pm 0.8$ & 1.10 & 0.95 & $3.60 \pm 0.09^{a}$ & 0.021 & 3.10 & $943^{d}$ & 296 & \\
\hline Beenham & $\mathrm{L} 5$ & Find & & 3.3 & 3.6 & $9.8 \pm 0.7$ & 0.73 & 0.43 & $1.83 \pm 0.04^{\mathrm{a}}$ & 0.028 & 1.08 & $761^{d}$ & 296 & \\
\hline Bluff & L5 & Find & W2 & 3.2 & 3.7 & $12.3 \pm 0.9$ & 1.12 & 0.70 & $3.20 \pm 0.08^{\mathrm{a}}$ & 0.032 & 1.98 & $885^{d}$ & 296 & \\
\hline Bluff* & L5 & Find & W2 & 3.2 & 3.7 & $12.3 \pm 0.9$ & 1.10 & 0.68 & $3.17 \pm 0.07^{a}$ & 0.032 & 1.96 & $895^{d}$ & 296 & \\
\hline Taiban & L5 & Find & & 3.3 & 3.7 & $8.7 \pm 0.9$ & 1.14 & 0.83 & $3.19 \pm 0.09^{\mathrm{a}}$ & 0.026 & 2.32 & $839^{d}$ & 296 & \\
\hline Taiban* & L5 & Find & & 3.3 & 3.7 & $8.7 \pm 0.9$ & 1.07 & 0.79 & $3.31 \pm 0.12^{\mathrm{a}}$ & 0.026 & 2.42 & $921^{d}$ & 296 & \\
\hline Tsarev & L5 & Find & & 3.3 & 3.6 & $8.8 \pm 0.9$ & 1.05 & 0.77 & $3.32 \pm 0.17^{\mathrm{a}}$ & 0.026 & 2.42 & $963^{d}$ & 296 & \\
\hline Tsarev* & L5 & Find & & 3.3 & 3.6 & $8.8 \pm 0.9$ & 1.15 & 0.84 & $3.29 \pm 0.12^{\mathrm{a}}$ & 0.026 & 2.39 & $872^{d}$ & 296 & \\
\hline Ausson & L5 & Fall & & 3.2 & 3.8 & $15.1 \pm 1.1$ & 0.58 & 0.22 & $1.56 \pm 0.04^{\mathrm{a}}$ & 0.036 & 0.60 & $834^{d}$ & 296 & \\
\hline Sevrukovo & L5 & Fall & & 3.4 & 3.8 & $8.9 \pm 1.2$ & 0.99 & 0.69 & $2.90 \pm 0.08^{a}$ & 0.026 & 2.04 & $857^{d}$ & 296 & \\
\hline Neenach & L6 & Find & & 3.3 & 3.9 & $14.5 \pm 1.1$ & 0.82 & 0.38 & $2.18 \pm 0.06^{a}$ & 0.035 & 1.02 & $798^{d}$ & 296 & \\
\hline
\end{tabular}




\begin{tabular}{|c|c|c|c|c|c|c|c|c|c|c|c|c|c|c|}
\hline Meteorite & Class & Fall & $\begin{array}{l}\text { Weathering } \\
\text { grade** }\end{array}$ & $\begin{array}{l}\text { Bulk } \\
\text { density } \\
\left(\mathrm{g} / \mathrm{cm}^{3}\right)\end{array}$ & $\begin{array}{l}\text { Grain } \\
\text { density } \\
\left(\mathrm{g} / \mathrm{cm}^{3}\right)\end{array}$ & Porosity (\%) & $\begin{array}{l}\text { Thermal } \\
\text { diffusivity } \\
\left(\mathrm{mm}^{2} / \mathrm{s}\right)\end{array}$ & $\begin{array}{l}\text { Corrected } \\
\text { thermal } \\
\text { diffusivity } \\
\left(1.33 \times 10^{-4}\right. \\
\mathrm{Pa})\left(\mathrm{mm}^{2} / \mathrm{s}\right)\end{array}$ & $\begin{array}{l}\text { Thermal } \\
\text { conductivity } \\
(\mathrm{W} / \mathrm{m} / \mathrm{K})\end{array}$ & $\begin{array}{l}\text { Aspect } \\
\text { ratio of } \\
\text { pores }\end{array}$ & $\begin{array}{l}\text { Corrected } \\
\text { thermal } \\
\text { conductivity } \\
\left(1.33 \times 10^{-4}\right. \\
\mathrm{Pa})(\mathrm{W} / \mathrm{m} / \mathrm{K})\end{array}$ & $\begin{array}{l}\text { Specific } \\
\text { heat } \\
\text { capacity } \\
(\mathrm{J} / \mathrm{kgK})\end{array}$ & Temp. (K) & Notes \\
\hline Neenach* & L6 & Find & & 3.3 & 3.9 & $14.5 \pm 1.1$ & 0.79 & 0.37 & $2.14 \pm 0.08^{\mathrm{a}}$ & 0.035 & 0.99 & $808^{d}$ & 296 & \\
\hline Valkeala & L6 & Find & & 3.4 & 3.4 & $2.4 \pm 0.1$ & 1.03 & 0.94 & $2.98 \pm 0.11^{\mathrm{a}}$ & 0.018 & 2.73 & $861^{d}$ & 296 & \\
\hline Valkeala* & L6 & Find & & 3.4 & 3.4 & $2.4 \pm 0.1$ & 0.95 & 0.87 & $3.15 \pm 0.05^{\mathrm{a}}$ & 0.018 & 2.90 & $985^{d}$ & 296 & \\
\hline Alfianello! & L6 & Fall & & 3.2 & 3.6 & $9.9 \pm 0.9$ & 0.61 & 0.31 & $1.21 \pm 0.02^{\mathrm{a}}$ & 0.028 & 0.62 & $610^{\mathrm{d}}$ & 296 & \\
\hline Alfianello*! & L6 & Fall & & 3.2 & 3.6 & $9.9 \pm 0.9$ & 0.58 & 0.29 & $1.15 \pm 0.04^{\mathrm{a}}$ & 0.028 & 0.58 & $617^{d}$ & 296 & \\
\hline Bath Furnace & L6 & Fall & & 3.4 & 3.8 & $10.9 \pm 1.1$ & 0.87 & 0.51 & $2.19 \pm 0.41^{\mathrm{a}}$ & 0.029 & 1.28 & $745^{d}$ & 296 & \\
\hline Bath Furnace* & L6 & Fall & & 3.4 & 3.8 & $10.9 \pm 1.1$ & 0.79 & 0.48 & $2.46 \pm 0.14^{\mathrm{a}}$ & 0.029 & 1.49 & $919^{d}$ & 296 & \\
\hline Richfield & LL3.7 & Find & & 3.4 & & & 0.85 & & $2.87 \pm 0.11^{\mathrm{a}}$ & & & $1000^{d}$ & 296 & \\
\hline Richfield* & LL3.7 & Find & & 3.4 & & & 0.69 & & $2.89 \pm 0.08^{a}$ & & & $1250^{d}$ & 296 & \\
\hline Arcadia 1 & LL6 & Find & & 3.1 & 3.4 & $9.0 \pm 0.9$ & 0.72 & 0.48 & $2.36 \pm 0.20^{\mathrm{a}}$ & 0.027 & 1.55 & $1043^{d}$ & 296 & \\
\hline Arcadia 2 & LL6 & Find & & 3.1 & 3.6 & $12.6 \pm 1.1$ & 0.72 & 0.38 & $2.18 \pm 0.09^{\mathrm{a}}$ & 0.032 & 1.14 & $955^{d}$ & 296 & \\
\hline Lake Labyrinth & LL6 & Find & & 3.2 & & & 0.37 & & $1.63 \pm 0.16^{a}$ & & & $1397^{d}$ & 296 & \\
\hline Lake Labyrinth* & LL6 & Find & & 3.2 & & & 0.47 & & $1.64 \pm 0.08^{\mathrm{a}}$ & & & $1096^{d}$ & 296 & \\
\hline Dhurmsala & LL6 & Fall & & 3.3 & 3.7 & $11.6 \pm 1.1$ & 0.79 & 0.43 & $1.96 \pm 0.03^{\mathrm{a}}$ & 0.030 & 1.05 & $754^{d}$ & 296 & \\
\hline Dhurmsala* & LL6 & Fall & & 3.3 & 3.7 & $11.6 \pm 1.1$ & 0.75 & 0.39 & $1.87 \pm 0.11^{\mathrm{a}}$ & 0.030 & 0.98 & $759^{d}$ & 296 & \\
\hline Jelica & LL6 & Fall & & 3.1 & 3.7 & $16.5 \pm 1.1$ & 0.16 & 0.05 & $1.19 \pm 0.02^{\mathrm{a}}$ & 0.039 & 0.35 & $2388^{\mathrm{d}}$ & 296 & \\
\hline Bondoc & Mesosiderite-B4 & Find & & 3.2 & 3.6 & $10.0 \pm 0.9$ & 0.76 & & $3.01 \pm 0.30^{\mathrm{a}}$ & & & $1219^{d}$ & 296 & \\
\hline Bondoc* & Mesosiderite-B4 & Find & & 3.2 & 3.6 & $10.0 \pm 0.9$ & 0.82 & & $2.73 \pm 0.56^{\mathrm{a}}$ & & & $1031^{d}$ & 296 & \\
\hline Bendegó & Iron, IC & Find & & 7.5 & 8.1 & $7.6 \pm 2.0$ & & & $12.93 \pm 0.46^{\mathrm{a}}$ & & & & 296 & \\
\hline Bella Roca & Iron, III AB & Find & & 7.8 & 8.2 & $5.0 \pm 2.7$ & & & $10.97 \pm 0.18^{\mathrm{a}}$ & & & & 296 & \\
\hline Canyon City & Iron, III AB & Find & & 7.4 & 8.2 & $8.8 \pm 2.3$ & & & $10.44 \pm 0.14^{\mathrm{a}}$ & & & & 296 & \\
\hline \multicolumn{15}{|c|}{ Szurgot et al. (2014) } \\
\hline NWA 4560 & LL3.2 & Find & & & & & 0.8 & & $4.6 \pm 0.10$ & & & & 200 & 4 \\
\hline NWA 4560 & LL3.2 & Find & & & & & 0.9 & & $4.10 \pm 1.3$ & & & & 300 & 4 \\
\hline \multicolumn{15}{|c|}{ Wach et al. (2014) } \\
\hline Kilabo & LL6 & Fall & & & & & & & $4.9 \pm 1.10$ & & & & 200 & 5 \\
\hline Kilabo & LL6 & Fall & & & & & & & $4.5 \pm 1.10$ & & & 690 & 300 & 5 \\
\hline \multicolumn{15}{|l|}{ Opeil et al. (2012) } \\
\hline Pillistfer & EL6 & Fall & & 3.6 & 3.7 & 2.4 & & & $5.51 \pm 0.01^{b}$ & & & & 200 & 6 \\
\hline Pultusk & H5 & Fall & & 3.4 & 3.7 & 7.5 & & & $1.25 \pm 0.01^{b}$ & & & & 200 & 6 \\
\hline Barbotan & H5 & Fall & & 3.5 & 3.8 & 6.9 & & & $3.05 \pm 0.01^{b}$ & & & & 200 & 6 \\
\hline Collescipoli & H5 & Fall & & 3.5 & & 9.1 & & & $0.82 \pm 0.01^{b}$ & & & & 200 & 1,6 \\
\hline La Ciénega & H6 & Find & & & & & & & $1.90 \pm 0.01^{b}$ & & & & 200 & 6 \\
\hline Holbrook 1 & L/LL6 & Fall & & 3.2 & 3.6 & 10.4 & & & $0.45 \pm 0.01^{b}$ & & & & 200 & 6 \\
\hline Holbrook 2 & L/LL6 & Fall & & 3.2 & 3.6 & 10.4 & & & $1.15 \pm 0.01^{b}$ & & & & 200 & 6 \\
\hline Bath Furnace 3 & L6 & Fall & & 3.5 & 3.7 & 4.3 & & & $3.15 \pm 0.01^{b}$ & & & & 200 & 6 \\
\hline Bath Furnace 2 & L6 & Fall & & 3.5 & 3.7 & 4.3 & & & $2.72 \pm 0.01^{b}$ & & & & 200 & 6 \\
\hline Bath Furnace 1 & L6 & Fall & & 3.5 & 3.7 & 4.3 & & & $2.26 \pm 0.01^{b}$ & & & & 200 & 6 \\
\hline Frankfort & Howardite & Fall & & 2.9 & 3.3 & 12.7 & & & $1.31 \pm 0.01^{b}$ & & & & 200 & 6 \\
\hline Frankfort & Howardite & Fall & & 2.9 & 3.3 & 12.7 & & & $1.60 \pm 0.01^{b}$ & & & & 300 & 6 \\
\hline Los Angeles & Shergottite & Find & & 2.8 & 3.1 & 8.1 & & & $0.77 \pm 0.01^{b}$ & & & & 200 & 6 \\
\hline Los Angeles & Shergottite & Find & & 2.8 & 3.1 & 8.1 & & & $0.90 \pm 0.01^{b}$ & & & & 300 & 6 \\
\hline
\end{tabular}




\begin{tabular}{|c|c|c|c|c|c|c|c|c|c|c|c|c|c|c|}
\hline Meteorite & Class & Fall & $\begin{array}{l}\text { Weathering } \\
\text { grade** }\end{array}$ & $\begin{array}{l}\text { Bulk } \\
\text { density } \\
\left(\mathrm{g} / \mathrm{cm}^{3}\right)\end{array}$ & $\begin{array}{l}\text { Grain } \\
\text { density } \\
\left(\mathrm{g} / \mathrm{cm}^{3}\right)\end{array}$ & Porosity (\%) & $\begin{array}{l}\text { Thermal } \\
\text { diffusivity } \\
\left(\mathrm{mm}^{2} / \mathrm{s}\right)\end{array}$ & $\begin{array}{l}\text { Corrected } \\
\text { thermal } \\
\text { diffusivity } \\
\left(1.33 \times 10^{-4}\right. \\
\mathrm{Pa}\left(\mathrm{mm}^{2} / \mathrm{s}\right)\end{array}$ & $\begin{array}{l}\text { Thermal } \\
\text { conductivity } \\
\text { (W/m/K) }\end{array}$ & $\begin{array}{l}\text { Aspect } \\
\text { ratio of } \\
\text { pores }\end{array}$ & $\begin{array}{l}\text { Corrected } \\
\text { thermal } \\
\text { conductivity } \\
\left(1.33 \times 10^{-4}\right. \\
\mathrm{Pa})(\mathrm{W} / \mathrm{m} / \mathrm{K})\end{array}$ & $\begin{array}{l}\text { Specific } \\
\text { heat } \\
\text { capacity } \\
(\mathrm{J} / \mathrm{kgK})\end{array}$ & Temp. (K) & Notes \\
\hline Soltmany & L6 & Fall & & & & & 1.50 & & $3.90 \pm 0.20^{c}$ & & & & 300 & 7 \\
\hline Soltmany & L6 & Fall & & & & & 1.80 & & $4.50 \pm 0.30^{c}$ & & & & 300 & 7 \\
\hline Soltmany & L6 & Fall & & & & & & & $4.70 \pm 0.30^{c}$ & & & & 200 & 7 \\
\hline Soltmany & L6 & Fall & & & & & & & $5.10 \pm 0.30^{c}$ & & & & 200 & 7 \\
\hline \multicolumn{15}{|l|}{ Szurgot (2011) } \\
\hline NWA 4039 & Eucrite & Find & & & & & 0.41 & & $1.10 \pm 0.10^{c}$ & & & & 300 & 8 \\
\hline HaH 286 & Eucrite & Find & & & & & 0.93 & & $1.90 \pm 0.01^{c}$ & & & & 300 & 8 \\
\hline Allende & CV3 & Fall & & 2.9 & 3.7 & 21.9 & 0.56 & & $1.40 \pm 0.10^{c}$ & & & $874^{d}$ & 300 & 2,8 \\
\hline DaG 610 & $\mathrm{H} 4$ & Find & & & & & 1.64 & & $2.50 \pm 0.20^{c}$ & & & & 300 & 8 \\
\hline Gold Basin & L4 & Find & W2-3 & 3.4 & 3.5 & 3.0 & 1.32 & & $3.70 \pm 0.20^{c}$ & & & $824^{d}$ & 300 & 2,8 \\
\hline El Hammami & $\mathrm{H} 5$ & Find & & 3.4 & 3.8 & 10.2 & 1.57 & & $4.50 \pm 0.30 c$ & & & $843^{d}$ & 300 & 2,8 \\
\hline Vaca Muerta & Mesosiderite-A1 & Find & & 3.1 & 3.1 & 1.2 & 1.34 & & $2.50 \pm 0.20 c$ & & & $600^{d}$ & 300 & 2,8 \\
\hline Brahin & Pallasite PMG & Find & & & & & 2.1 & & $5.40 \pm 0.30^{c}$ & & & & 300 & 8 \\
\hline Brahin & Pallasite PMG & Find & & & & & 6.9 & & $16.50 \pm 0.90^{c}$ & & & & 300 & 8 \\
\hline Odessa & IAB-MG & Find & & 7.1 & & & 12.4 & & $45 \pm 3^{c}$ & & & $508^{d}$ & 300 & 2,8 \\
\hline Campo del Cielo & IAB-MG & Find & & & & & 15.8 & & $52 \pm 3^{c}$ & & & & 300 & 8 \\
\hline Gibeon & IVA & Find & & & & & 7.2 & & $23 \pm 1^{c}$ & & & & 300 & 8 \\
\hline Gibeon & IVA & Find & & & & & & & $25 \pm 2^{c}$ & & & & 300 & 8 \\
\hline \multicolumn{15}{|l|}{ Opeil et al. (2010) } \\
\hline Abee & EH6 & Fall & & 3.5 & 3.6 & 3.0 & & & $5.35 \pm 0.01^{b}$ & & & 500 & 200 & 9 \\
\hline Cronstad & H5 & Fall & & & & & & & $1.88 \pm 0.01^{b}$ & & & 550 & 200 & 9 \\
\hline Lumpkin & L6 & Fall & & 3.7 & & & & & $1.47 \pm 0.01^{b}$ & & & 570 & 200 & 1,9 \\
\hline NWA 5515 & CK4 & Find & & 2.7 & & & & & $1.48 \pm 0.01^{b}$ & & & 500 & 200 & 3,9 \\
\hline Cold Bokkeveld & $\mathrm{CM} 2$ & Fall & & 2.4 & 2.8 & 15.0 & & & $0.50 \pm 0.01^{\mathrm{b}}$ & & & 500 & 200 & 9 \\
\hline Campo del Cielo & IAB-MG & Find & & & & & & & $22.40 \pm 0.01^{b}$ & & & 375 & 200 & 9 \\
\hline \multicolumn{15}{|c|}{ Beech et al. (2009) } \\
\hline Gao-Guenie & $\mathrm{H} 5$ & Fall & & & & & & & $2.99 \pm 0.15^{c}$ & & & 732 & 300 & 10 \\
\hline \multicolumn{15}{|c|}{ Szurgot et al. (2008) } \\
\hline Morasko & IAB-MG & Find & & & & & & & $25 \pm 1$ & & & 478 & 293 & 11 \\
\hline Morasko & IAB-MG & Find & & & & & & & $50 \pm 2$ & & & & 301 & 11 \\
\hline Morasko & IAB-MG & Find & & & & & & & $35 \pm 2$ & & & & 301 & 11 \\
\hline Morasko & IAB-MG & Find & & & & & & & $39 \pm 2$ & & & & 301 & 11 \\
\hline Morasko & IAB-MG & Find & & & & & & & $51 \pm 2$ & & & & 301 & 11 \\
\hline Morasko & IAB-MG & Find & & & & & & & $67 \pm 2$ & & & & 301 & 11 \\
\hline \multicolumn{15}{|c|}{ Yomogida and Matsui (1983) } \\
\hline ALHA77288 & H6 & Find & c & 3.7 & 3.8 & 2.0 & 1.75 & & 3.53 & & & $547^{d}$ & 200 & 12 \\
\hline ALHA77288 & H6 & Find & C & 3.7 & 3.8 & 2.0 & 1.11 & & 2.96 & & & $723^{d}$ & 300 & 12 \\
\hline ALHA77294 & H5 & Find & $\mathrm{Ae}$ & 3.4 & 3.8 & 12.9 & 0.41 & & 0.75 & & & $551^{d}$ & 200 & 12 \\
\hline ALHA77294 & H5 & Find & $\mathrm{Ae}$ & 3.4 & 3.8 & 12.9 & 0.26 & & 0.63 & & & $721^{d}$ & 300 & 12 \\
\hline Gilgoin & H5 & Find & & 3.6 & 3.8 & 5.0 & 1.82 & & 3.6 & & & $548^{d}$ & 200 & 12 \\
\hline Gilgoin & H5 & Find & & 3.6 & 3.8 & 5.0 & 1.34 & & 3.49 & & & $721^{d}$ & 300 & 12 \\
\hline Gladstone & $\mathrm{H} 4$ & Find & & 3.6 & 3.7 & 5.0 & 1.10 & & 2.16 & & & $552^{d}$ & 200 & 12 \\
\hline Gladstone & $\mathrm{H} 4$ & Find & & 3.6 & 3.7 & 5.0 & 0.89 & & 2.28 & & & $720^{d}$ & 300 & 12 \\
\hline
\end{tabular}




\begin{tabular}{|c|c|c|c|c|c|c|c|c|c|c|c|c|c|c|}
\hline Meteorite & Class & Fall & $\begin{array}{l}\text { Weathering } \\
\text { grade** }\end{array}$ & $\begin{array}{l}\text { Bulk } \\
\text { density } \\
\left(\mathrm{g} / \mathrm{cm}^{3}\right)\end{array}$ & $\begin{array}{l}\text { Grain } \\
\text { density } \\
\left(\mathrm{g} / \mathrm{cm}^{3}\right)\end{array}$ & Porosity (\%) & $\begin{array}{l}\text { Thermal } \\
\text { diffusivity } \\
\left(\mathrm{mm}^{2} / \mathrm{s}\right)\end{array}$ & $\begin{array}{l}\text { Corrected } \\
\text { thermal } \\
\text { diffusivity } \\
\left(1.33 \times 10^{-4}\right. \\
\mathrm{Pa})\left(\mathrm{mm}^{2} / \mathrm{s}\right)\end{array}$ & $\begin{array}{l}\text { Thermal } \\
\text { conductivity } \\
(W / m / K)\end{array}$ & $\begin{array}{l}\text { Aspect } \\
\text { ratio of } \\
\text { pores }\end{array}$ & $\begin{array}{l}\text { Corrected } \\
\text { thermal } \\
\text { conductivity } \\
\left(1.33 \times 10^{-4}\right. \\
\mathrm{Pa}(\mathrm{W} / \mathrm{m} / \mathrm{K})\end{array}$ & $\begin{array}{l}\text { Specific } \\
\text { heat } \\
\text { capacity } \\
(\mathrm{J} / \mathrm{kgK})\end{array}$ & Temp. (K) & Notes \\
\hline Monroe & $\mathrm{H} 4$ & Fall & & 3.6 & 3.8 & 5.9 & 1.20 & & 2.35 & & & $547^{d}$ & 200 & 12 \\
\hline Monroe & $\mathrm{H} 4$ & Fall & & 3.6 & 3.8 & 5.9 & 0.87 & & 2.26 & & & $726^{d}$ & 300 & 12 \\
\hline Wellman & H5 & Find & & 3.6 & 3.8 & 6.1 & 1.96 & & 3.85 & & & $549^{d}$ & 200 & 12 \\
\hline Wellman & H5 & Find & & 3.6 & 3.8 & 6.1 & 1.37 & & 3.54 & & & $722^{d}$ & 300 & 12 \\
\hline Y-74156 & $\mathrm{H} 4$ & Find & & 3.6 & 3.9 & 9.2 & 0.81 & & 1.54 & & & $529^{d}$ & 200 & 12 \\
\hline Y-74156 & $\mathrm{H} 4$ & Find & & 3.6 & 3.9 & 9.2 & 0.62 & & 1.55 & & & $698^{d}$ & 300 & 12 \\
\hline Y-74647 & $\mathrm{H} 4.5$ & Find & & 3.5 & 3.8 & 9.1 & 0.60 & & 1.15 & & & $546^{d}$ & 200 & 12 \\
\hline Y-74647 & $\mathrm{H} 4.5$ & Find & & 3.5 & 3.8 & 9.1 & 0.46 & & 1.15 & & & $724^{d}$ & 300 & 12 \\
\hline ALHA76009 & L6 & Find & B & 2.9 & 3.6 & 19.4 & 0.34 & & 0.55 & & & $565^{d}$ & 200 & 12 \\
\hline ALHA76009 & L6 & Find & B & 2.9 & 3.6 & 19.4 & 0.27 & & 0.58 & & & $754^{d}$ & 300 & 12 \\
\hline ALHA77231 & L6 & Find & $\mathrm{A} / \mathrm{Be}$ & 3.1 & 3.6 & 14.3 & 0.64 & & 1.2 & & & $610^{d}$ & 200 & 12 \\
\hline ALHA77231 & L6 & Find & $\mathrm{A} / \mathrm{Be}$ & 3.1 & 3.6 & 14.3 & 0.49 & & 1.13 & & & $759^{d}$ & 300 & 12 \\
\hline ALHA78103 & L6 & Find & B & 3.2 & 3.7 & 13.4 & 0.40 & & 0.73 & & & $569^{d}$ & 200 & 12 \\
\hline ALHA78103 & L6 & Find & B & 3.2 & 3.7 & 13.4 & 0.28 & & 0.69 & & & $760^{d}$ & 300 & 12 \\
\hline ALHA78251 & L6 & Find & B & 3.2 & 3.7 & 13.2 & 0.47 & & 0.85 & & & $566^{d}$ & 200 & 12 \\
\hline ALHA78251 & L6 & Find & B & 3.2 & 3.7 & 13.2 & 0.29 & & 0.72 & & & $761^{d}$ & 300 & 12 \\
\hline Arapahoe & L5 & Find & & 3.5 & 3.6 & 2.5 & 1.15 & & 2.31 & & & $571^{d}$ & 200 & 12 \\
\hline Arapahoe & L5 & Find & & 3.5 & 3.6 & 2.5 & 1.00 & & 2.55 & & & $728^{d}$ & 300 & 12 \\
\hline Bruderheim & L6 & Fall & & 3.3 & 3.6 & 8.0 & 0.55 & & 1.03 & & & $567^{d}$ & 200 & 12 \\
\hline Bruderheim & L6 & Fall & & 3.3 & 3.6 & 8.0 & 0.39 & & 0.98 & & & $759^{d}$ & 300 & 12 \\
\hline Farmington & L5 & Fall & & 3.4 & 3.6 & 5.5 & 1.11 & & 2.14 & & & $567^{d}$ & 200 & 12 \\
\hline Farmington & L5 & Fall & & 3.4 & 3.6 & 5.5 & 0.95 & & 2.44 & & & $758^{d}$ & 300 & 12 \\
\hline Kunashak & L6 & Fall & & 3.4 & 3.6 & 5.2 & 0.96 & & 1.86 & & & $569^{d}$ & 200 & 12 \\
\hline Kunashak & L6 & Fall & & 3.4 & 3.6 & 5.2 & 0.77 & & 1.98 & & & $759^{d}$ & 300 & 12 \\
\hline Leedey, A & L6 & Fall & & 3.3 & 3.6 & 10.4 & 0.22 & & 0.4 & & & $567^{d}$ & 200 & 12 \\
\hline Leedey, A & L6 & Fall & & 3.3 & 3.6 & 10.4 & 0.17 & & 0.42 & & & $751^{d}$ & 300 & 12 \\
\hline Leedey, B & L6 & Fall & & 3.2 & 3.6 & 10.6 & 0.25 & & 0.47 & & & $573^{d}$ & 200 & 12 \\
\hline Leedey, B & L6 & Fall & & 3.2 & 3.6 & 10.6 & 0.20 & & 0.49 & & & $756^{d}$ & 300 & 12 \\
\hline META78003 & L6 & Find & B & 3.3 & 3.6 & 7.8 & 0.82 & & 1.54 & & & $567^{d}$ & 200 & 12 \\
\hline META78003 & L6 & Find & B & 3.3 & 3.6 & 7.8 & 0.63 & & 1.58 & & & $758^{d}$ & 300 & 12 \\
\hline New Concord & L6 & Fall & & 3.3 & 3.6 & 9.2 & 0.42 & & 0.78 & & & $568^{d}$ & 200 & 12 \\
\hline New Concord & L6 & Fall & & 3.3 & 3.6 & 9.2 & 0.31 & & 0.76 & & & $760^{d}$ & 300 & 12 \\
\hline Y-74191 & L3.7 & Find & A & 3.2 & 3.6 & 10.3 & 0.68 & & 1.24 & & & $569^{d}$ & 200 & 12 \\
\hline Y-74191 & L3.7 & Find & A & 3.2 & 3.6 & 10.3 & 0.54 & & 1.32 & & & $760^{d}$ & 300 & 12 \\
\hline Y-75097 & L6 & Find & A & 3.3 & 3.7 & 10.3 & 0.52 & & 0.97 & & & $569^{d}$ & 200 & 12 \\
\hline Y-75097 & L6 & Find & A & 3.3 & 3.7 & 10.3 & 0.39 & & 0.96 & & & $758^{d}$ & 300 & 12 \\
\hline \multicolumn{15}{|c|}{ Matsui and Osako (1979) } \\
\hline Y-74191 & L3.7 & Find & A & & & & & & 0.67 & & & 603 & 300 & 13 \\
\hline \multicolumn{15}{|c|}{ Butler and Jenkins (1963) } \\
\hline Canyon Diablo & IAB-MG & Find & & & & & & & 63 & & & 548 & 293 & 14 \\
\hline \multicolumn{15}{|l|}{ Wood (1963) } \\
\hline Norton County & Aubrite & Fall & & & & & & & 1.51 & & & & NA & 15 \\
\hline Orlovka & H5 & Find & & & & & & & 1.76 & & & & NA & 15 \\
\hline
\end{tabular}




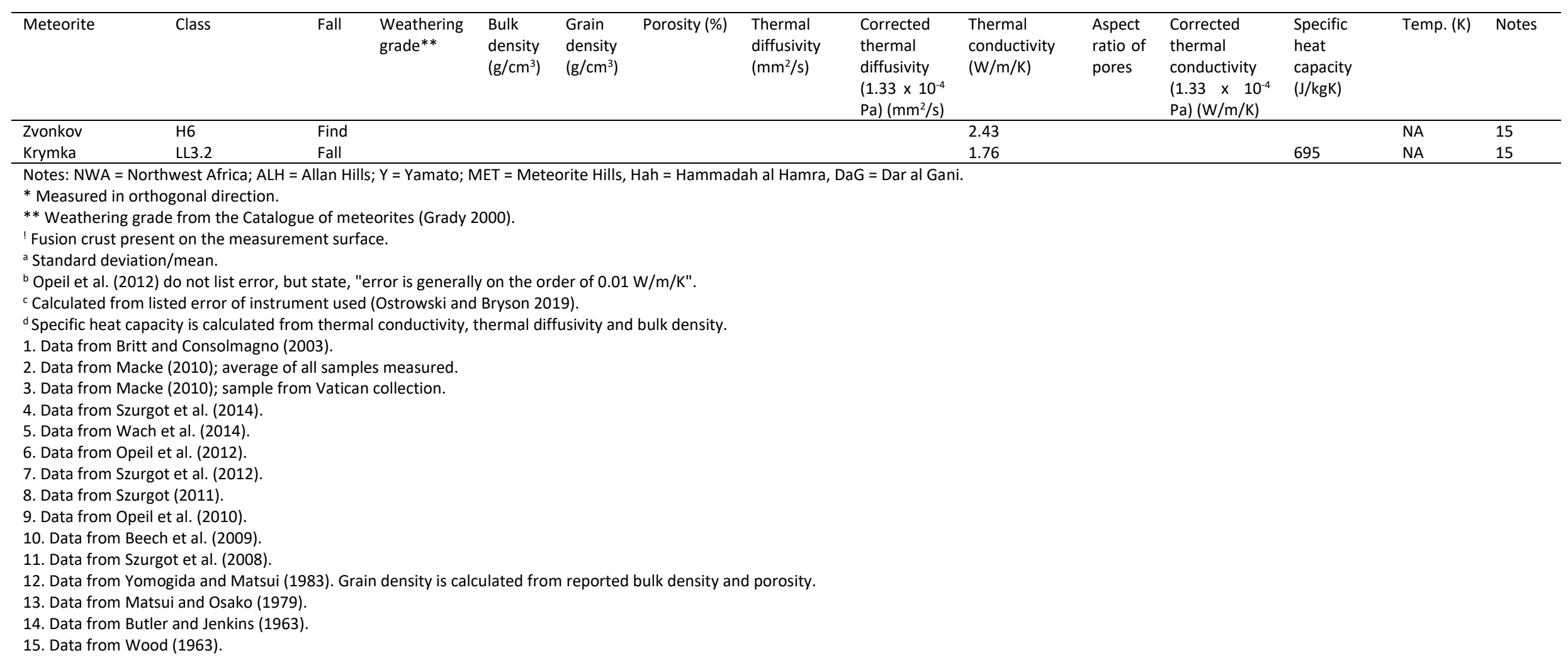


Table III. Class average and standard deviation of chondrites in Table 1. Number of the samples is given in parentheses. Conductivities represent data at $300 \mathrm{~K}$ and vacuum pressure.

\begin{tabular}{|c|c|c|c|}
\hline & All & Falls & Finds \\
\hline & \multicolumn{3}{|c|}{ H chondrites } \\
\hline \multicolumn{4}{|l|}{ This study } \\
\hline Average conductivity $(\mathrm{W} / \mathrm{m} / \mathrm{K})$ & $1.85 \pm 0.11(21)$ & - & $1.85 \pm 0.11(21)$ \\
\hline Average porosity (\%) & $11.2 \pm 1.1(12)$ & - & $11.2 \pm 1.1(12)$ \\
\hline \multicolumn{4}{|l|}{ All data* } \\
\hline Average conductivity (W/m/K) & $1.93 \pm 0.10(34)$ & $1.85 \pm 0.04(5)$ & $1.95 \pm 0.11(29)$ \\
\hline \multirow[t]{2}{*}{ Average porosity (\%) } & $9.3(24)$ & $7.35(4)$ & $9.7(20)$ \\
\hline & \multicolumn{3}{|c|}{ L chondrites } \\
\hline \multicolumn{4}{|l|}{ This study } \\
\hline Average conductivity (W/m/K) & $1.86 \pm 0.10(20)$ & $1.28 \pm 0.13(7)$ & $2.16 \pm 0.09(13)$ \\
\hline Average porosity (\%) & $9.3 \pm 0.9(12)$ & $10.0 \pm 1.0(5)$ & $8.7 \pm 0.8(7)$ \\
\hline \multicolumn{4}{|l|}{ All data* } \\
\hline Average conductivity (W/m/K) & $1.64 \pm 0.12(39)$ & $1.51 \pm 0.14(17)$ & $1.74 \pm 0.10(22)$ \\
\hline \multirow[t]{2}{*}{ Average porosity (\%) } & $9.2(28)$ & $8.6(12)$ & $9.7(16)$ \\
\hline & \multicolumn{3}{|c|}{ LL chondrites } \\
\hline \multicolumn{4}{|l|}{ This study } \\
\hline Average conductivity (W/m/K) & $1.02 \pm 0.10(5)$ & $0.80 \pm 0.06(3)$ & $1.35 \pm 0.12(6)$ \\
\hline Average porosity (\%) & $12.4 \pm 0.7(4)$ & $14.1 \pm 1.1(2)$ & $10.8 \pm 0.8(2)$ \\
\hline \multicolumn{4}{|l|}{ All data* } \\
\hline Average conductivity $(\mathrm{W} / \mathrm{m} / \mathrm{K})$ & $1.02 \pm 0.10(5)$ & $0.80 \pm 0.06(3)$ & $1.35 \pm 0.12(2)$ \\
\hline \multirow[t]{2}{*}{ Average porosity (\%) } & $12.4 \pm 0.7(4)$ & $14.1 \pm 1.1(2)$ & $10.8 \pm 0.8(2)$ \\
\hline & \multicolumn{3}{|c|}{ L/LL chondrites } \\
\hline \multicolumn{4}{|l|}{ This study } \\
\hline Average conductivity $(\mathrm{W} / \mathrm{m} / \mathrm{K})$ & $0.56 \pm 0.06(2)$ & $0.056 \pm 0.06(2)$ & - \\
\hline Average porosity (\%) & $14.3 \pm 0.6(1)$ & $14.3 \pm 0.6(1)$ & - \\
\hline \multicolumn{4}{|l|}{ All data* } \\
\hline Average conductivity $(\mathrm{W} / \mathrm{m} / \mathrm{K})$ & $0.68 \pm 0.04(4)$ & $0.68 \pm 0.04(4)$ & - \\
\hline \multirow[t]{2}{*}{ Average porosity (\%) } & $12.4(2)$ & $12.4(2)$ & - \\
\hline & \multicolumn{3}{|c|}{ C chondrites } \\
\hline \multicolumn{4}{|l|}{ This study } \\
\hline Average conductivity $(\mathrm{W} / \mathrm{m} / \mathrm{K})$ & $0.77 \pm 0.03(3)$ & $0.77 \pm 0.03(3)$ & - \\
\hline Average porosity (\%) & $14.6 \pm 0.6(2)$ & $14.6 \pm 0.6(2)$ & - \\
\hline \multicolumn{4}{|l|}{ All data* } \\
\hline Average conductivity (W/m/K) & $0.86 \pm 0.04(5)$ & $0.70 \pm 0.04(4)$ & $1.48 \pm 0.01(1)$ \\
\hline \multirow[t]{2}{*}{ Average porosity (\%) } & $16.5(4)$ & $16.5(4)$ & - \\
\hline & \multicolumn{3}{|c|}{ E chondrites } \\
\hline \multicolumn{4}{|l|}{ This study } \\
\hline Average conductivity $(\mathrm{W} / \mathrm{m} / \mathrm{K})$ & $0.63 \pm 0.09(1)$ & $0.63 \pm 0.09(1)$ & - \\
\hline Average porosity (\%) & $22.6 \pm 1.4(1)$ & $22.6 \pm 1.4(1)$ & - \\
\hline \multicolumn{4}{|l|}{ All data* } \\
\hline Average conductivity $(\mathrm{W} / \mathrm{m} / \mathrm{K})$ & $3.83 \pm 0.04(3)$ & $3.83 \pm 0.04(3)$ & - \\
\hline Average porosity (\%) & $9.3(3)$ & $9.3(3)$ & - \\
\hline
\end{tabular}




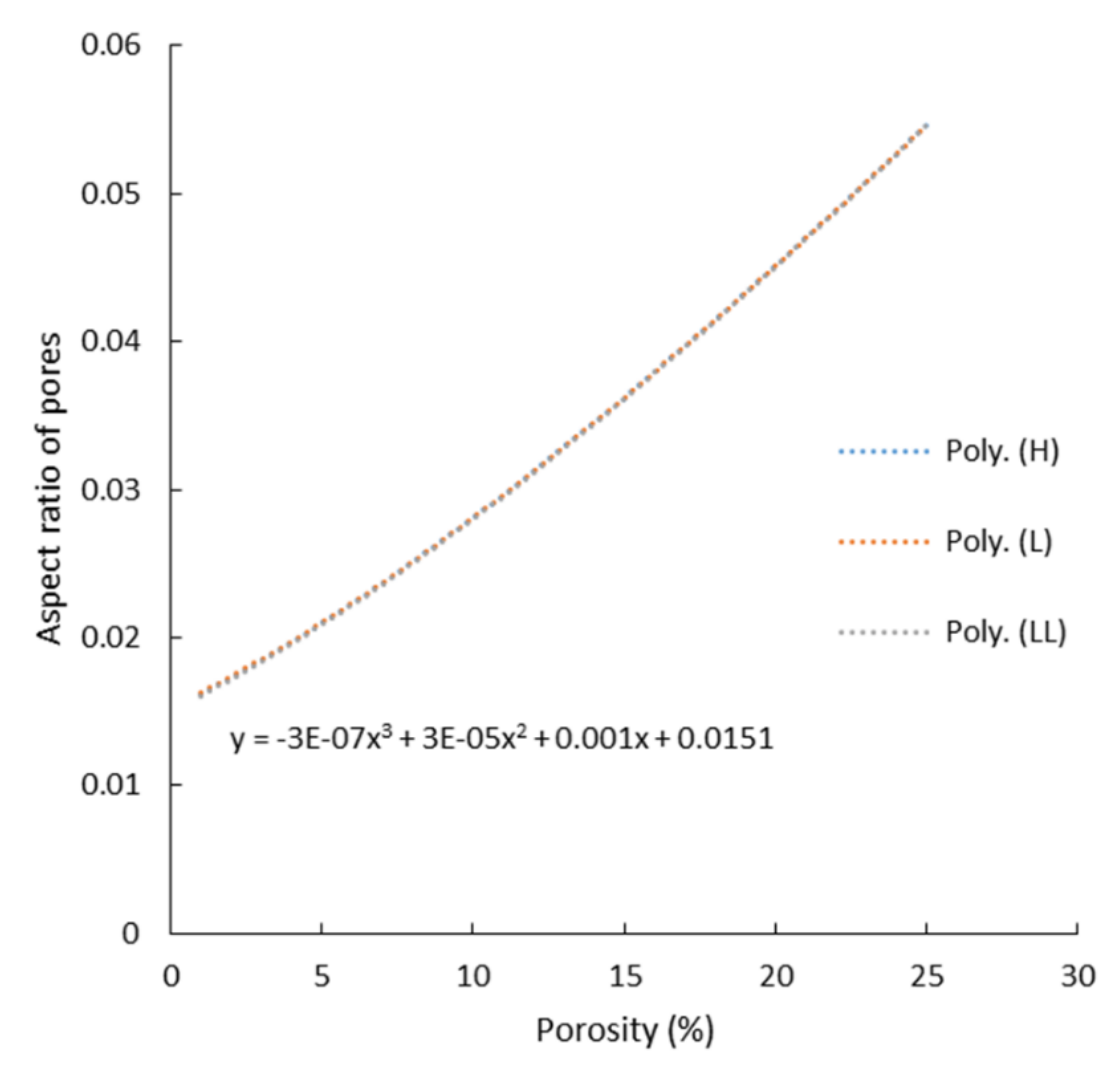

Fig. 1. Relationship between the aspect ratio of pores and porosity.

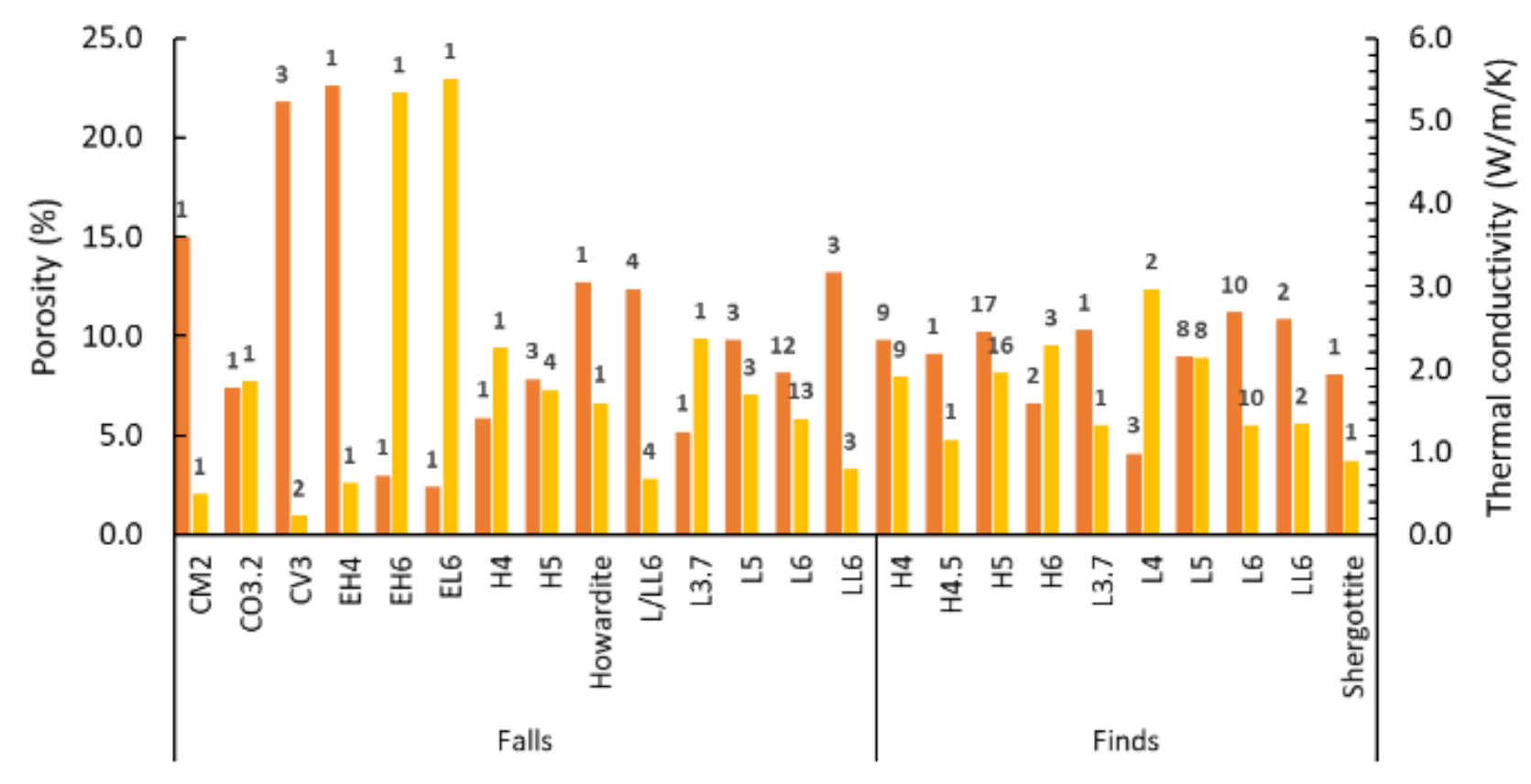

Fig. 2. Thermal conductivities $(300 \mathrm{~K})$ and porosities of the results in this study combined with literature data. Average thermal conductivities are calculated from results at low pressures of this study, Opeil et al. (2010, 2012), Yomogida and Matsui (1983) and Matsui and Osako (1979). The number above each bar is the number of the samples. 


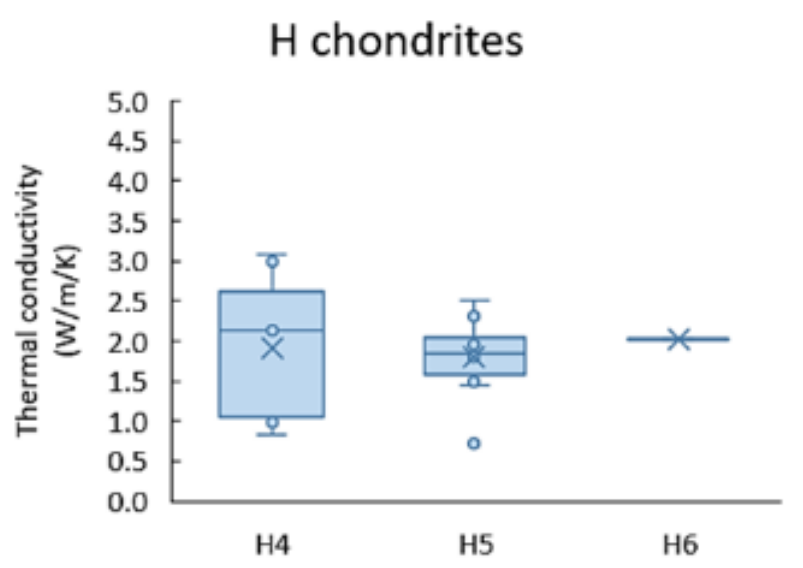

LL chondrites

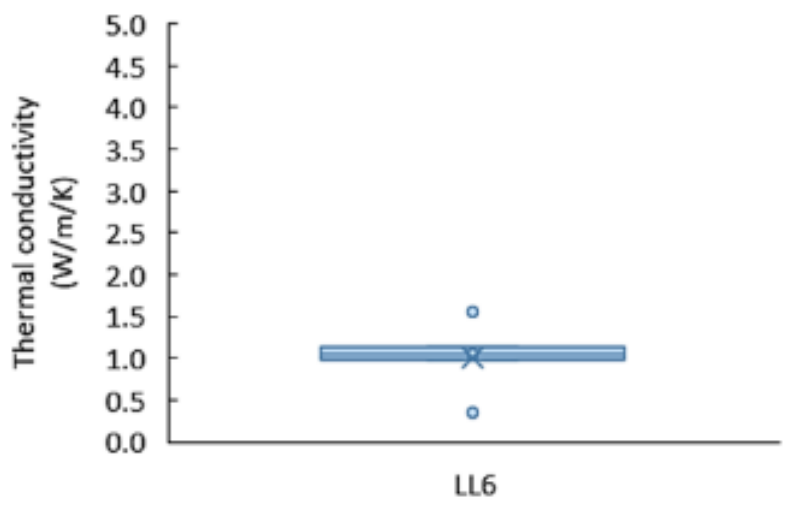

\section{L chondrites}

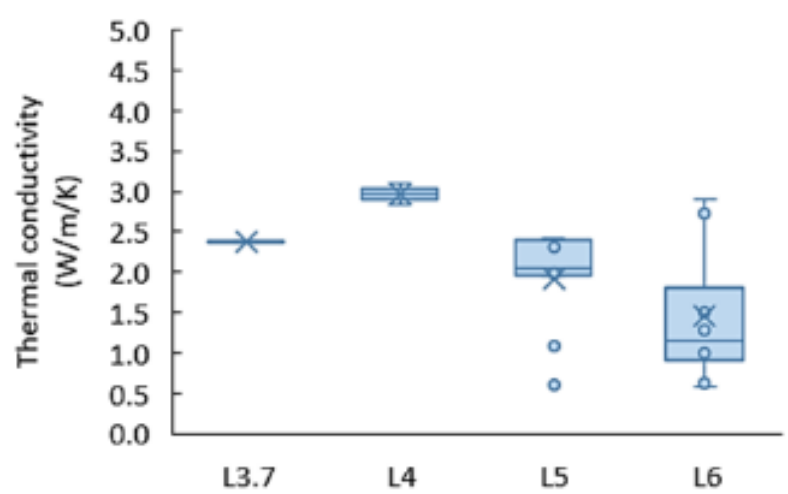

L/LL chondrites

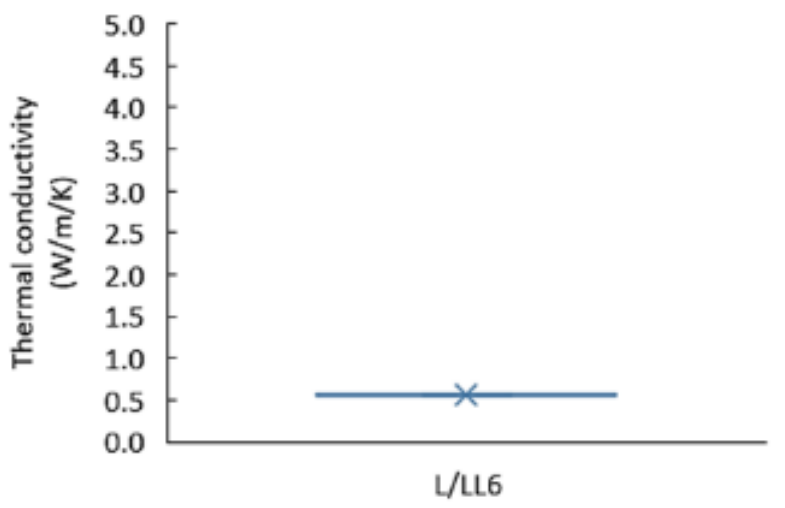

Fig. 3. Thermal conductivities (300 K and vacuum conditions) of ordinary chondrite classes in this study including falls and finds. Boxes are bounded by the third and first quartile and median divides the bar. The lower quartile is the median of the lower half of the data and the upper quartile is the median of the upper half of the data. Bars display the error and extend to the maximum and minimum. Both inner data points and outlier points are shown. The cross is the mean marker. 


\section{$\mathrm{H}$ chondrites}

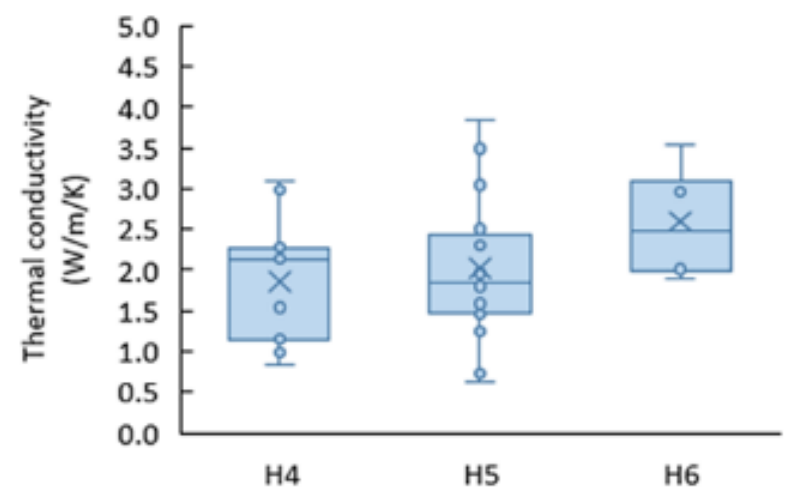

LL chondrites

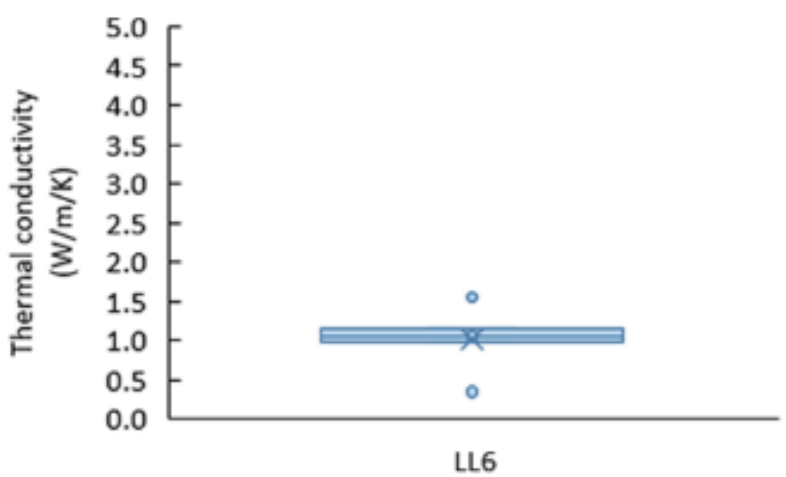

L chondrites

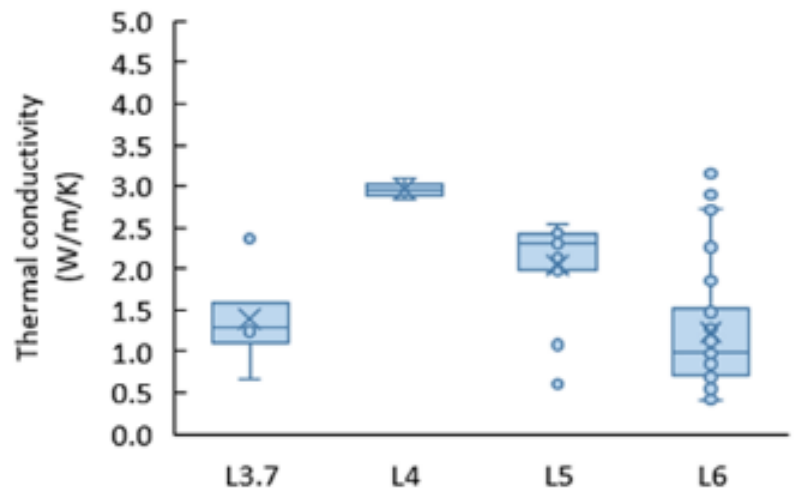

L/LL chondrites

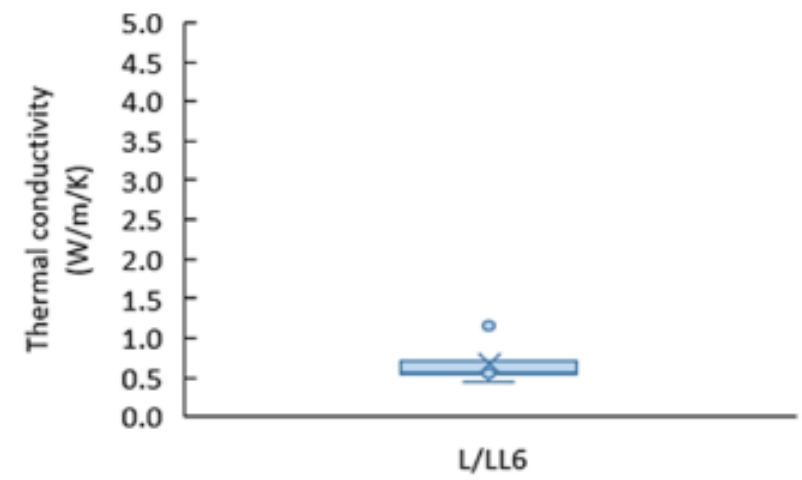

Fig. 4. Thermal conductivities (vacuum conditions) of ordinary chondrite classes in the compiled data in Table 2. Boxes are bounded by the third and first quartile and median divides the bar. The lower quartile is the median of the lower half of the data and the upper quartile is the median of the upper half of the data. Bars display the error and extend to the maximum and minimum. Both inner data points and outlier points are shown. The cross is the mean marker. 


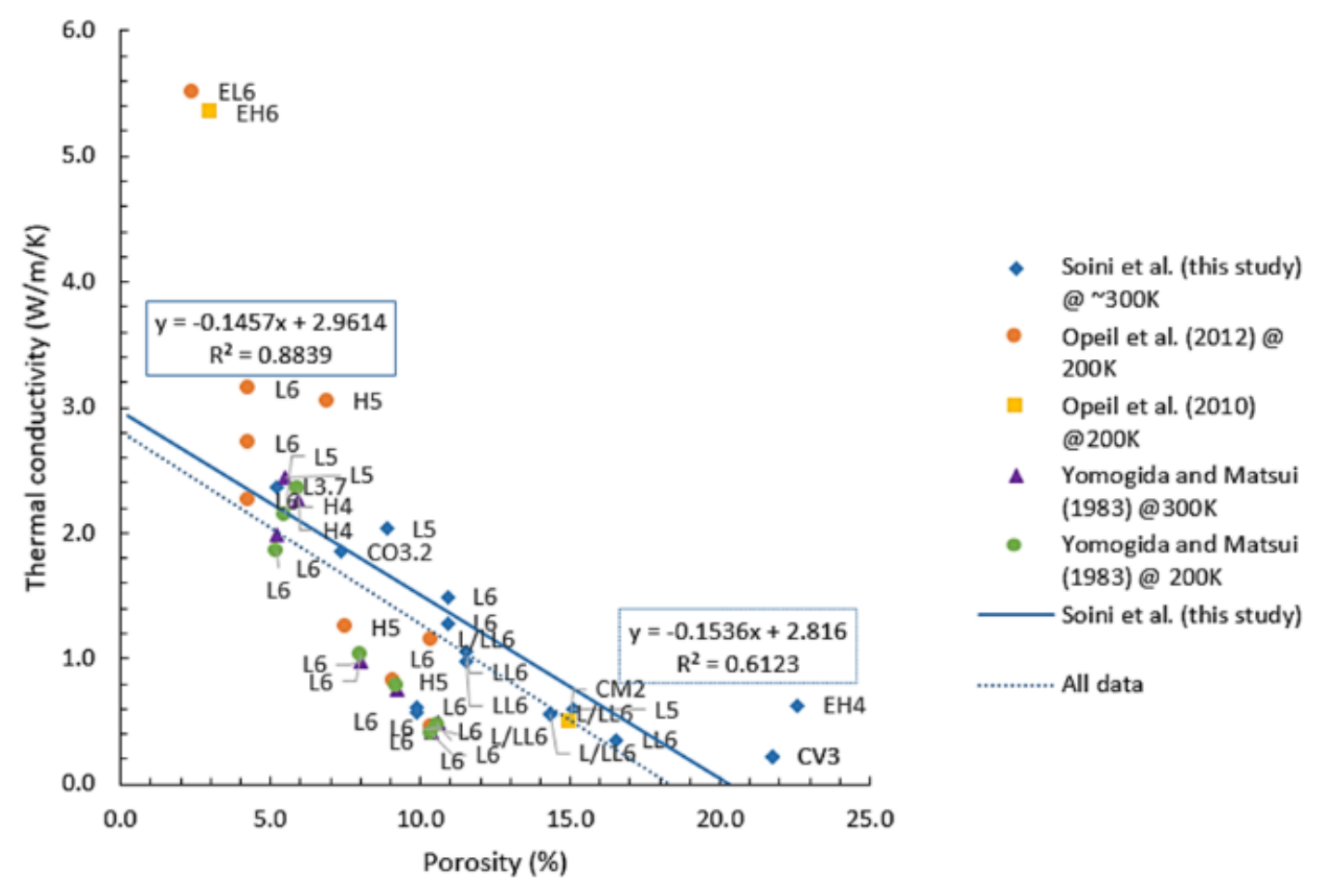

Fig. 5. Relationship between thermal conductivity (low pressure) and porosity of chondrite falls. $R$ squared values of 0.88 and 0.61 represent data in this study and all data, respectively. Chondrites Abee, Alfianello, and Pillistfer are not included in the correlations.

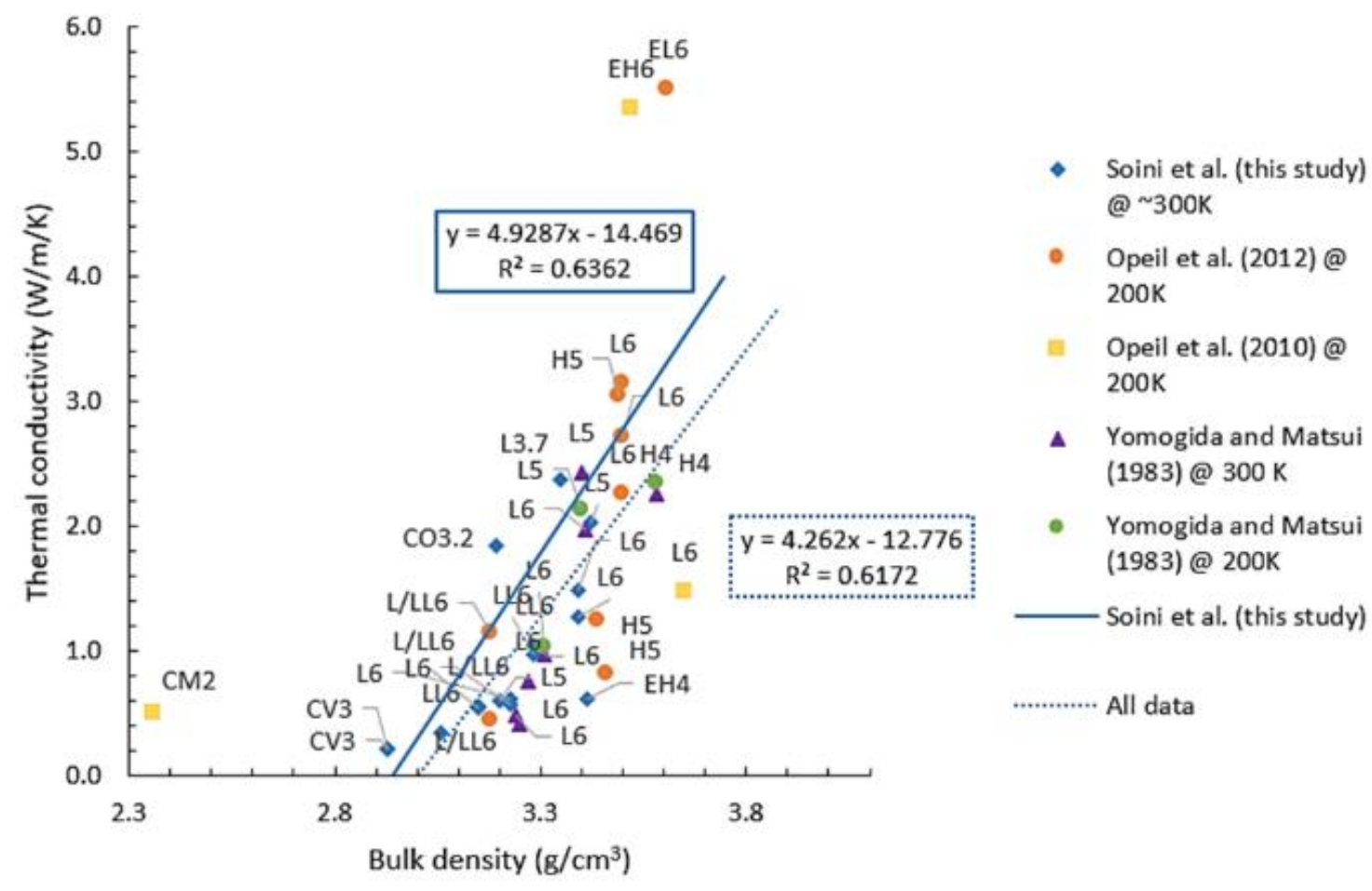

Fig. 6. Relationship between thermal conductivity (low pressure) and bulk density of chondrite falls in the compiled database. $R$-squared values of 0.64 and 0.62 represent data in this study and all data, respectively. Chondrites Abee, Alfianello, Pillistfer, and Cold Bokkeveld are not included in the correlations. 


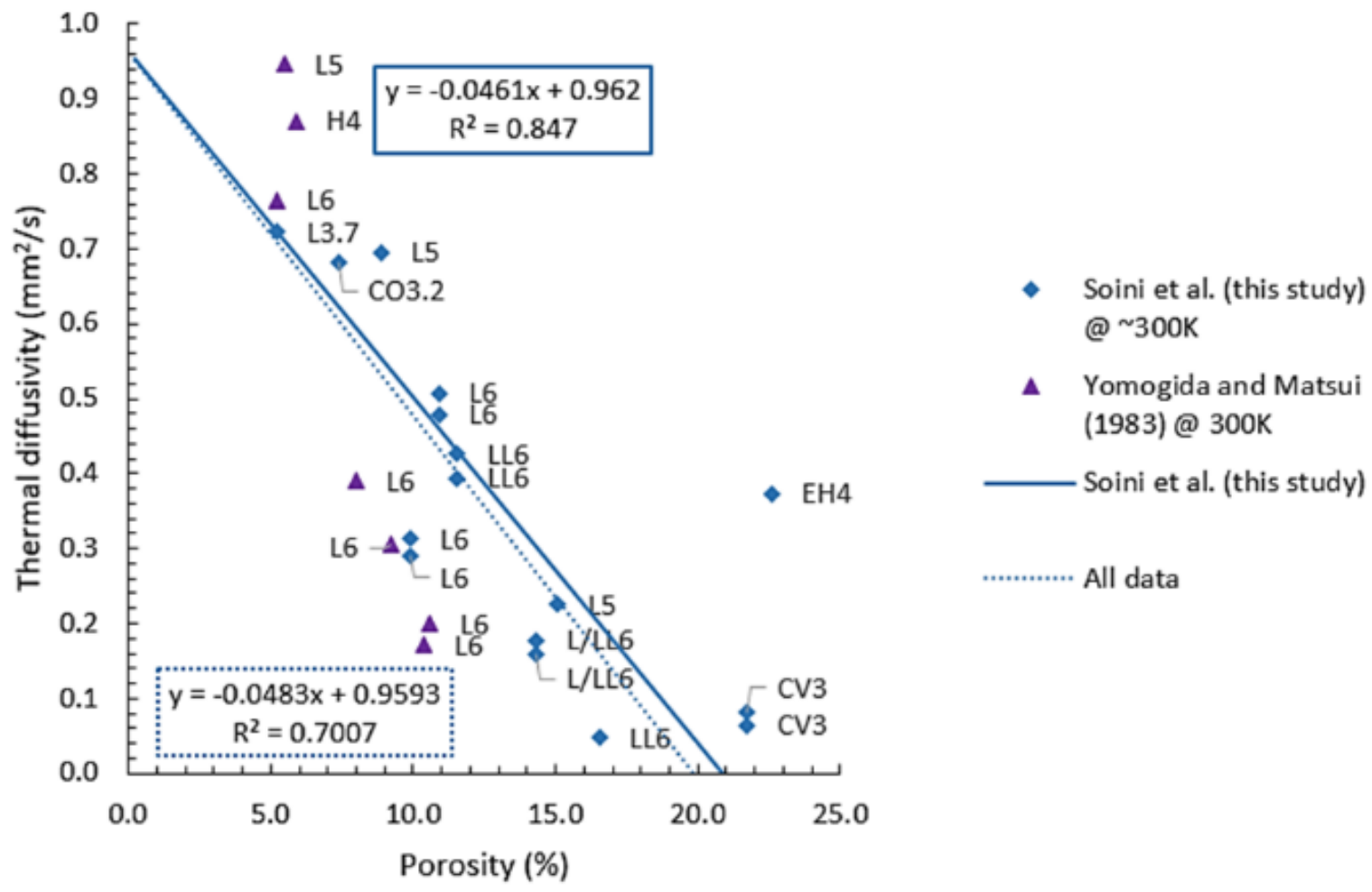

Fig. 7. Relationship between thermal diffusivity and porosity of chondrite falls in the compiled database. $R$-squared values of 0.85 and 0.70 represent data in this study and all data, respectively. Chondrites Abee and Alfianello are not included in the correlations.

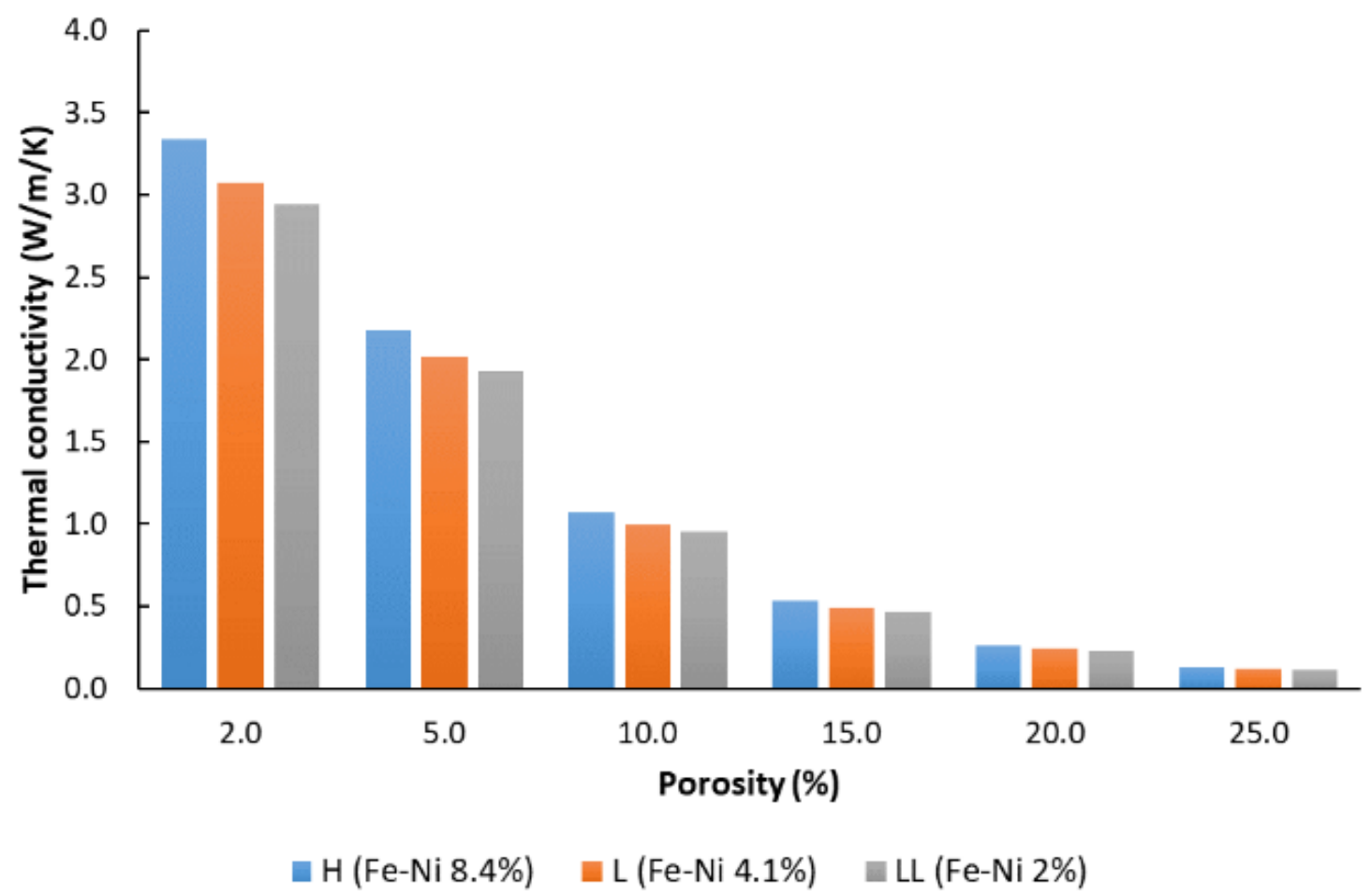

Fig. 8. Thermal conductivities for model compositions of $H, L$, and $L L$ chondrites under vacuum (1.33 $\left.x 10^{-4} \mathrm{~Pa}\right)$. 


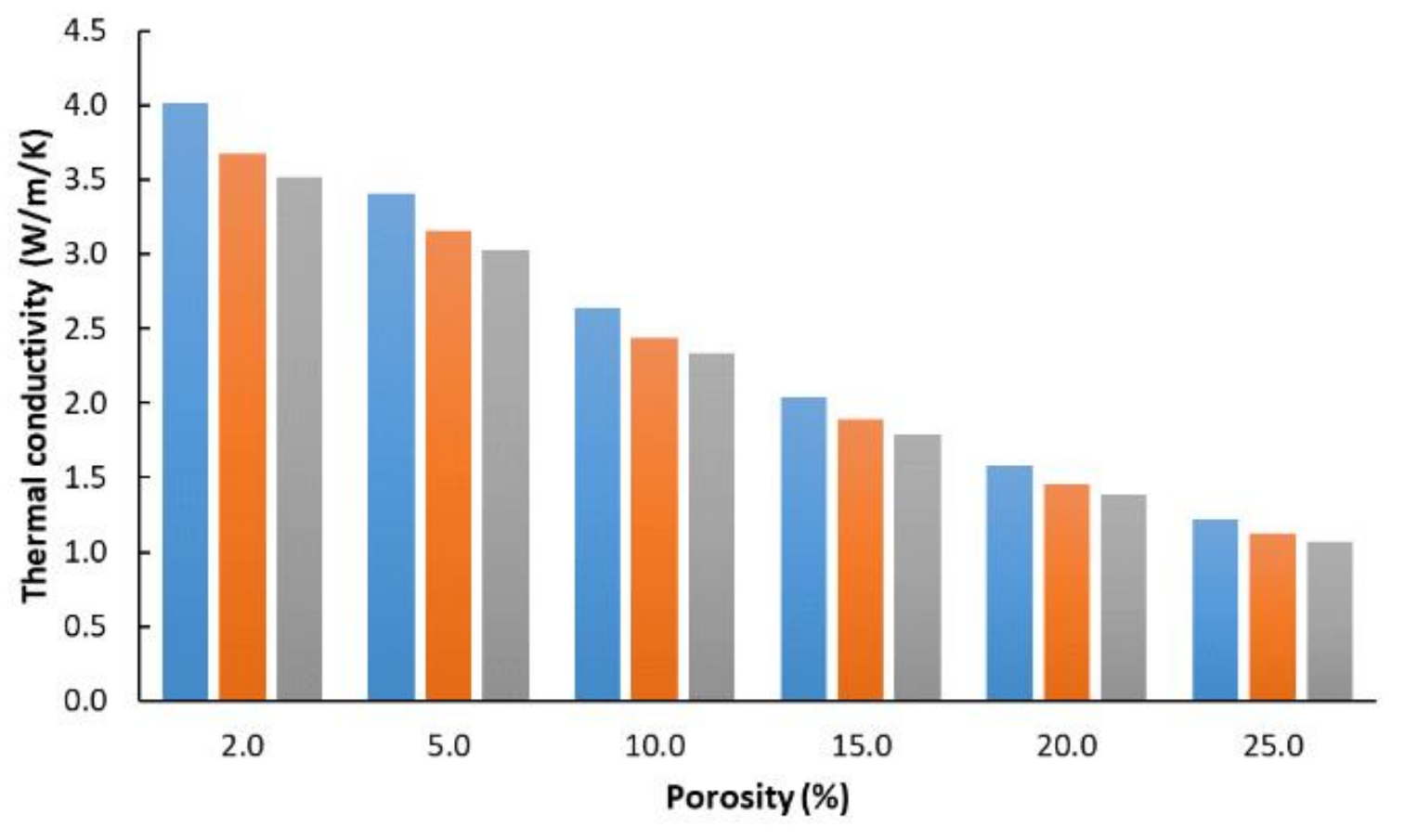

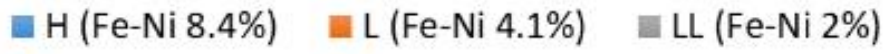

Fig. 9. Thermal conductivities for model compositions of $H, L$, and LL chondrites at 1 atm.
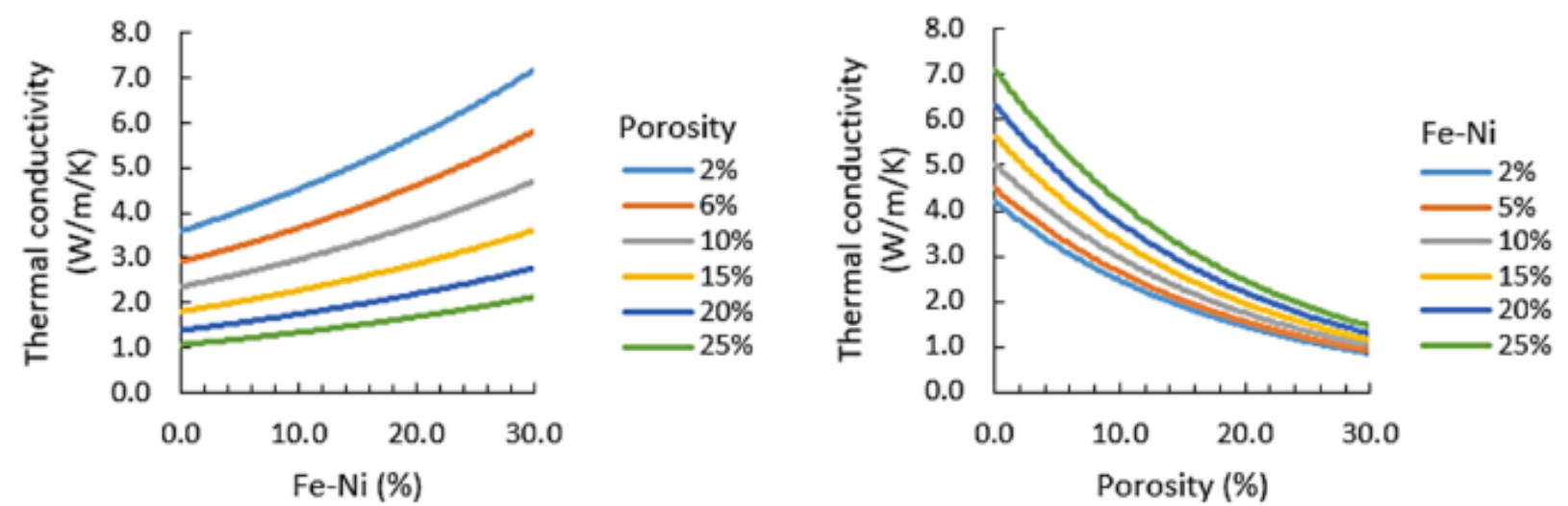

Fig. 10. Thermal conductivity in ambient air of different theoretical compositions of meteorites. 


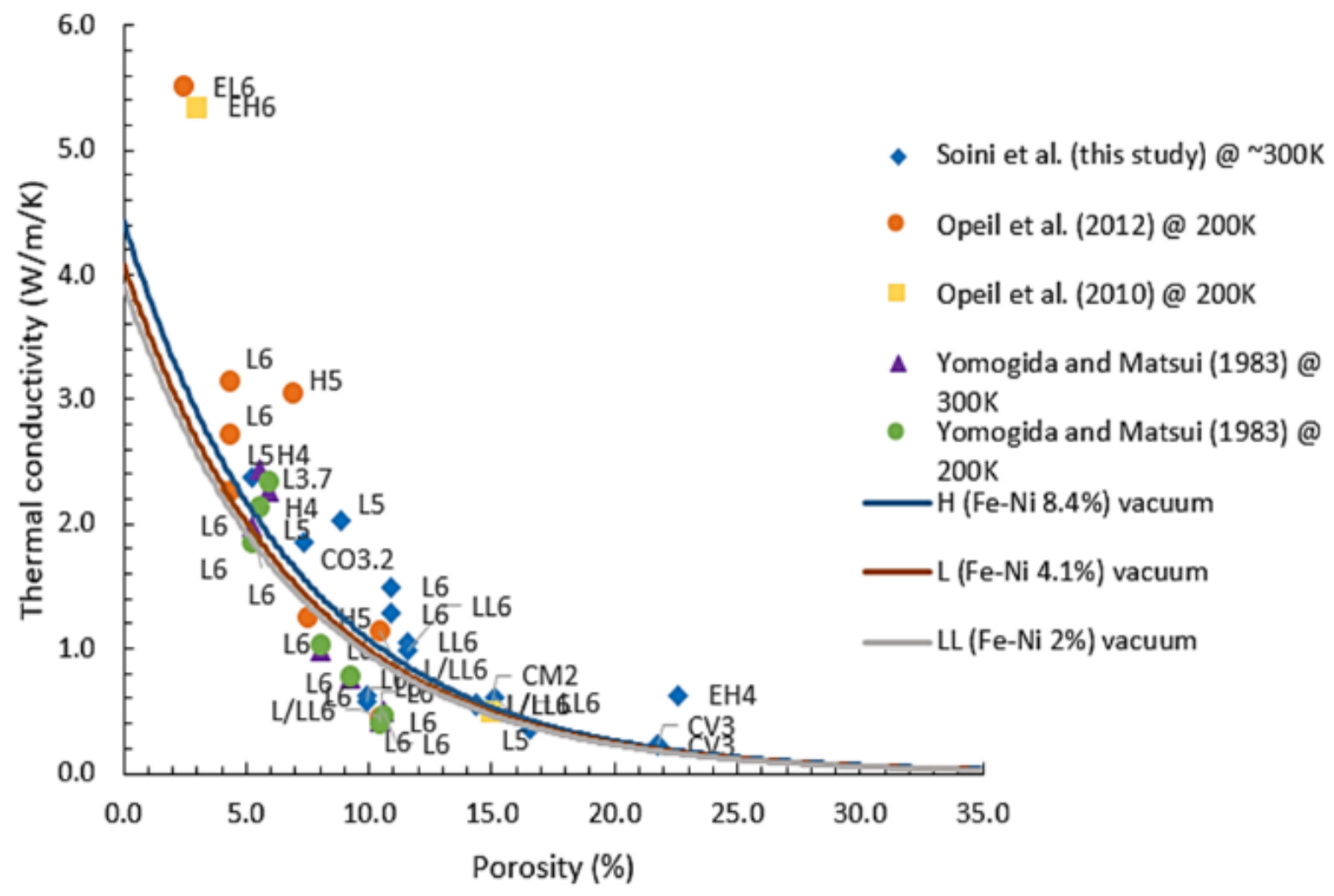

Fig. 11. Thermal conductivities and porosities of falls in the compiled database in Table 2 with thermal conductivities for model compositions of $H, L$, and $L L$ chondrites near vacuum with air pressure of $1.33 \times 10^{-4} \mathrm{~Pa}$. The results of this study show the corrected thermal conductivities. 